\title{
"Berlín, 1907”. \\ La reconstrucción de un recuerdo de juventud de Carl Schmitt
}

\author{
Kilian LAVERNIA BIESCAS \\ kilianlavernia@gmail.com \\ Universidad Nacional de Educación a Distancia
}

El siguiente estudio sobre el inédito de Carl Schmitt titulado "Berlín, 1907" persigue dos objetivos de distinto calado' ${ }^{1}$.

En primer lugar, en un nivel que podríamos definir como técnico, las reflexiones iniciales estarán dedicadas a contextualizar debidamente este texto dentro de un complejo periodo de la obra schmittiana -aquel que comprende los años inmediatamente posteriores a la Segunda Guerra Mundial-, cuya importancia no ha sido atendida todavía con el suficiente interés y rigor que merece. En segundo lugar, una vez se hayan precisado algunas líneas maestras de dicho perido, se abordarán algunas de las claves interpretativas del texto propiamente dicho. En concreto, el estudio desarrollará, desde los distintos accesos a los que nos invita el texto schmittiano, el tema de la transformación cultural del genialismo en Alemania y su difícil relación con la problemática del Yo, esto es, la producción de subjetividad genialística a principios del siglo XX.

\section{I}

\section{La datación y redacción del texto y su extraño lugar en la obra de Schmitt entre los años 1945 y 1950}

A día de hoy, existen dos fuentes que reproducen dos historias bien distintas acerca del surgimiento de este curioso texto schmittiano. Su coexistencia es cuando menos problemática, de ahí que una correcta elucidación de cada una de las versiones sea ineludible por necesaria.

La primera fuente parecería en principio la más fiable, ya que su protagonista es, de hecho, el primer y único editor de este inédito, el belga Piet Tommissen. Tommissen relata en su breve introducción que Schmitt, al regalarle en privado una copia

\footnotetext{
${ }^{1}$ El texto de Carl Schmitt se encuentra al final del presente estudio, en traducción al español realizada por el autor.
} 
del manuscrito en abril de 1965, no sólo le habría explicado que el texto "había sido escrito en el frío invierno de hambrunas de 1946/47", sino que su redacción "había sido alentada por un jurista español; muy a mi pesar, no pude retener su nombre"2. En todo caso, concluye el editor, Schmitt habría autorizado su publicación, aunque no es menos cierto que ésta se hizo efectiva algunos años después de su muerte.

La segunda fuente procede de la valiosa correspondencia que Schmitt mantiene desde 1930 con su amigo Ernst Jünger. Tras una larga interrupción, que se extiende desde julio de 1945 a enero de 1947 -y que coincide, por tanto, con el periodo de internamiento de Schmitt en dos camps americanos, desde los que sólo puede cartearse mensualmente con su esposa ${ }^{3}$, el Briefwechsel se reanuda con una carta de agradecimiento a Jünger con fecha del 24 de enero. En ella, el jurista le agradece sus cartas que recibió durante el internamiento y que no pudo contestar. Fueron y siguen siendo, escribe, "un maravilloso alivio" (ein wunderbarer Trost). Junto a la carta, Schmitt adjunta un breve escrito, un polémico texto que rememoraba la indefensión que había experimentado al enfrentarse, en verano de 1945, con el nuevo rector de la Universidad de Berlín, el filósofo Eduard Spranger. Y a continuación añade:

El texto es estrictamente personal; como algunos otros textos de esta naturaleza, surgieron bajo el impulso de sueños determinados fonéticamente [unter dem Antrieb phonetisch determinierter Träume], así, p.e., uno sobre Tocqueville, otro sobre dos tumbas en Berlín (la tumba de Kleist y la de Däubler) y otro sobre dos catedráticos de mi primer semestre berlinés, cuya voz todavía sigo escuchando. En ocasiones, tales sueños son profundamente mortificantes; aun así, no me gustaría dejar escapar el extraño atractivo que tienen para mít.

El lector atento se habrá dado cuenta de que Schmitt está avanzando a su amigo una parte del futuro contenido de Ex captivitate salus [ECS], cuya publicación no verá la luz hasta el año $1950^{5}$. En efecto, tanto el texto sobre Spranger como el de

\footnotetext{
${ }^{2}$ Cfr. "Introducción a 'Berlín, 1907””, en Schmittiana I, P. Tommissen (ed.), Bruselas, Economische Hogeschool Sint-Aloysius, 1988, p. 12. Para el texto propiamente dicho, cfr. ibidem, pp. 13-21.

${ }^{3}$ A petición del legal adviser del Gobierno Militar, Karl Löwenstein - un antiguo conocido de Schmitt emigrado a finales de 1933-, Schmitt fue arrestado el 26 de septiembre de 1945 y llevado al Centro de interrogatorio Berlín-Wannsee; de ahí pasó, primero, desde el 31 de octubre, al Internierungslager Lichterfelde-Süd, luego, a partir de enero de 1946, al Civilian Detention Camp junto al Wannsee. Su caso fue tratado el 27 de junio de 1946 por la Comisión de Seguridad y Examen alemana y su puesta en libertad se formalizó el 2 de agosto, aunque debido a la lentitud burocrática no sería excarcelado hasta el 10 de octubre. Sobre su periodo de internamiento, cfr. R. Mehring, Carl Schmitt. Aufstieg und Fall. Eine Biographie, Múnich, C.H. Beck, 2009, pp. 442-445, pero también J. W. Bendersky, "Carl Schmitt's Path to Nuremberg: A Sixty-Year Reassessment”, en Telos 139, 2007, pp. 6-34.

${ }^{4}$ Cfr. Ernst Jünger/Carl Schmitt. Briefwechsel 1930-1983, H. Kiesel (ed.), Stuttgart, Klett-Cotta, 1999, p. 195 ss.

${ }^{5}$ C. Schmitt, Ex captivitate salus. Erfahrungen der Zeit 1945/47, Colonia, Greven-Verlag, 1950. En
} 
Tocqueville y el de las dos tumbas berlinesas serían incorporados, algunos años después, a ese inclasificable libro que recogía las producciones schmittianas destiladas durante la experiencia, personal e intransferible, de la soledad y el aislamiento de la inmediata posguerra.

Sin embargo, el mismo lector atento habrá percibido también la manifiesta incompatibilidad de las dos versiones que reproducen el surgimiento del texto que aquí nos ocupa. Por un lado, Tommissen, en calidad de editor y amigo de Schmitt, no sólo afirma que habría sido escrito en el "frío invierno de hambrunas de 1946/47", sino que insiste, además, en que su redacción habría estado motivada, animada o alentada (ermuntert) por un jurista español cuya identidad permanece oculta. Por el otro, el hecho de que en enero de 1947 Schmitt sea capaz de confiarle a Jünger la existencia de una serie de textos de marcado carácter personal -entre los cuales figura "Berlín, 1907"-, los cuales han sido elaborados a partir de determinados sueños que fueron surgiendo a lo largo del internamiento berlinés, permite concluir también que su confección coincide con el turbulento periodo en los camps americanos entre septiembre de 1945 y octubre de 1946, y, por consiguiente, pertenecería al contexto de surgimiento de ECS. La hipótesis de la naturaleza onírica de dichos textos sería ciertamente sorprendente, sugerente, muy en la línea del propio Jünger y su inconfundible tratamiento literario de los sueños. El guiño parece claro, aunque aquí, para centrarnos en el tema, no podamos sino sugerirlo a modo de intuición e invitar con ello a pensarlo en otro contexto de discusión.

En cualquier caso, la incongruencia entre ambas versiones radica en el hecho de que, aun siendo verdadera la versión de Tommissen, esto es, aun habiendo escrito el texto en invierno de 1946/47 e incluso siendo remotamente cierta la referencia al jurista español, la carta a Jünger abre un valioso horizonte de interpretación, ya que nos invita a reevaluar seriamente la importancia de "Berlín, 1907" desde su vinculación directa con los otros textos de 1945 y 1946 que conforman el entramado principal de ECS. Bajo esta luz, podríamos aventurar la hipótesis según la cual dicho texto formaría parte del conjunto de escritos fragmentarios que fueron redactados en secreto y enviados en forma de cartas a su mujer desde el Civilian Detention Camp en Wannsee ${ }^{6}$. Qué duda cabe, pues, de que estas cartas innegablemente privadas, de acceso restringido en el Nachlass schmittiano en Düsseldorf, ofrecerían algunas de las claves para entender el surgimiento de algunos de los temas que abordaremos en las siguientes páginas. De hecho, ha sido la reciente biografía de Reinhard Mehring

lo que sigue citaremos por la reciente edición española, cfr. Ex captivitate salus. Experiencias de la época, Madrid, Trotta, 2010.

${ }^{6}$ Señalaba Schmitt en el prólogo a la edición española de ECS que había sido el mérito de un médico estadounidense el que hubiera podido eludir la estricta prohibición de escribir que imperaba en el campo de Lichterfelde-Süd. Dicho médico, recordaba agradecido, no sólo había proporcionado material de escritura a los presos, sino "que incluso nos ayudó a sacar del campo cartas y notas sin pasar por el control de las autoridades" [ECS, 22]. 
la que nos ha puesto sobre la pista, ya que a ella debemos la transcripción de una de estas cartas, con fecha de enero de 1946. Se trata de una misiva que nos confirma la vinculación temática de "Berlín, 1907" con una de las experiencias fundamentales del camp americano, a saber, la constatación schmittiana de la psicosis colectiva entre los presos alemanes y la obsesión enfermiza con su propio Yo:

Usted no se puede hacer a la idea del estado anímico de los presos del campamento, que en la mayoría de los casos caen en una psicosis de Lager y día y noche maquinan toda suerte de combinaciones, siendo así que la obsesión con el Yo [Ich-Besessenheit] de los alemanes sale a la luz en unas dimensiones fantasmagóricas?

Como veremos más adelante, esta Ich-Besessenheit se convertirá en una categoría de análisis crucial; por ahora, sin embargo, nos limitaremos a concluir este primer apartado de tipo técnico recordando que Schmitt decidió finalmente no incorporar este texto a ECS, aunque lo conservó como un escrito privado que podía compartir con sus amigos y personas de confianza, como en el caso de Álvaro d'Ors, de quien tenemos constancia que leyó con entusiasmo la parte correspondiente al retrato de Wilamowitz ${ }^{8}$. Finalmente, en esta misma línea, tampoco podríamos olvidar el sutil ofrecimiento de un viejo Schmitt, en el marco de las tardías entrevistas concedidas a finales de 1971, por darlo a conocer en la radio alemana ${ }^{9}$.

\section{Los años de la inmediata posguerra: escribir en la soledad del silencio pero ganar espacio}

Estos compases iniciales, que han girado en principio sobre los problemas de datación y redacción de "Berlín, 1907", preparan en realidad una reflexión de carácter más general sobre la producción schmittiana entre los años 1945 y 1950. En este sentido, es imprescindible recordar que este texto no sólo pertenece, como hemos intentado demostrar, al contexto de surgimiento de ECS, sino revela también, en un

\footnotetext{
${ }^{7}$ Cit. por R. Mehring, op. cit., p. 443.

${ }^{8}$ Cfr. Carl Schmitt und Álvaro d'Ors: Briefwechsel, M. Herrero (ed.), Berlín, Duncker \& Humblot, 2004, pp. 128, 130 y 133. Por aquellos años (1952), el joven romanista andaba traduciendo el De legibus de Cicerón, y Schmitt consideró que sus propios recuerdos acerca de la manera en que Wilamowitz interpretó la figura del orador romano podrían serle de utilidad.

${ }^{9}$ Cfr. C. Schmitt, „Solange das Imperium da ist“. Carl Schmitt im Gespräch 1971, F. Hertweck y D. Kisoudis (eds.), Berlín, Duncker \& Humblot, 2010, pp. 78 s. El ofrecimiento de Schmitt respondía, en cierto modo, a la pregunta inicial de los entrevistadores (Dieter Groh y Klaus Figge) sobre las razones que le habían impulsado a decidirse por la carrera de Derecho, pregunta que fue pospuesta deliberadamente por el jurista (p. 38) hasta que consideró oportuno sugerir el manuscrito de "Berlin, 1907" como lectura radiofónica (p. 78). Este interesante ofrecimiento fue sin embargo declinado por los entrevistadores.
} 
siguiente nivel de análisis, su pertenencia a la órbita de aquellas otras obras que son Glossarium [G] y Respuestas en Núremberg [RN $]^{10}$.

Sería ciertamente insuficiente y hasta cierto punto equívoco hablar aquí de obras de marcado carácter autobiográfico. Antes bien, autobiográficos son, en un sentido estricto, los escritos de juventud que han venido publicándose en la última década, inaugurando así un campo de investigación que, a su vez, refleja con claridad aquella tendencia que Jens Hacke ha definido acertadamente como un innegable proceso de "historización" de la figura de Schmitt en Alemania". Pensemos, por ejemplo, en los Tagebücher del joven Schmitt, que han sido editados para los años 1912 a 1915, además de otros muchos y poco conocidos materiales, como aquéllos surgidos en Múnich en su doble condición de censor militar y escritor satírico para revistas literarias, irónica convivencia que se desarrollará armónicamente hasta $1919^{12}$; o recordemos el Briefwechsel que mantiene con su hermana Auguste de 1905 a $1913^{13}$. En ambos casos, su importancia radica en el hecho de que fijan las primeras estaciones formativas del pensamiento schmittiano, desde el encuentro capital con Theodor Däubler, entendido como lanzadera espiritual para numerosas inquietudes de orden estético-filosófico, hasta la crucial experiencia vivida de los tumultuosos años muniqueses, tanto durante la Gran Guerra como en la inmediata posguerra, años en los que por ejemplo brotan, casi de forma natural, las primeras reflexiones acerca de la normalización del estado de excepción y la diferencia entre la dictadura soberana y la dictadura comisaria. Por último, y como enésima prueba de que esta Historisierung tiene una clara continuidad en el actual panorama editorial alemán, cabría destacar la reciente publicación de nuevos materiales autobiográficos correspondientes a la época de Bonn, años clave, sin duda, que confirman el interés académico por explorar "desde dentro" las etapas de conquista intelectual del joven profesor de de-

\footnotetext{
${ }^{10}$ Citamos por las ediciones alemanas: Glossarium. Aufzeichnungen der Jahre 1947-1951, E. Freiherr von Medem (ed.), Berlín, Duncker \& Humblot, 1991 (actualmente descatalogada, si bien es cierto que la editorial acaba de anunciar este mes -septiembre 2015- una nueva edición, revisada y aumentada por G. Giesler y M. Tielke, cuya característica más importante es que incorpora la cuarta y quinta parte, es decir, las entradas hasta 1958); Antworten in Nürnberg, H. Quaritsch (ed.), Berlín, Duncker \& Humblot, 2000. La editorial Escolar y Mayo prepara una traducción de esta obra, realizada por quien suscribe este texto, cuya publicación está prevista para primavera de 2016.

11 "Die Historisierung Carl Schmitts schreitet unaufhaltsam voran", dice Hacke en su reciente reseña con ocasión de otra nueva correspondencia, Carl Schmitt - Ernst Rudolf Huber. Briefwechsel 1926-1981, E. Grothe (ed.), Berlín, Duncker \& Humblot, 2014, en H-Soz-Kult (23.01.2015), localizable bajo el siguiente enlace: $\mathrm{http}: /$ hsozkult.geschichte.hu-berlin.de/rezensionen/type=rezbuecher\&id=23750\&view=pdf]. ${ }^{12}$ Cfr. Carl Schmitt. Tagebücher vom Oktober 1912 bis Februar 1915, E. Hüsmert (ed.), Berlín, Akademie Verlag, 2003 (2a ed. revisada, 2005), así como Carl Schmitt. Die Militärzeit 1915 bis 1919. Tagebuch Februar bis Dezember 1915. Aufsätze und Materialien, E. Hüsmert y G. Giesler (eds.), Berlín, Akademie Verlag, 2005.

${ }^{13}$ Cfr. Carl Schmitt. Jugendbriefe. Briefschaften an seine Schwester Auguste 1905-1913, E. Hüsmert (ed.), Berlín, Akademie Verlag, 2000.
} 
recho $^{14}$. Algo parecido habría que decir, desde luego, con respecto a los Tagebücher de principios de los treinta, descifrados de momento hasta el año $1934^{15}$.

En cambio, el fácil equívoco al que pueden inducir los escritos comprendidos entre los años 1945 y 1950 es querer considerarlos autobiográficos por oposición a las grandes obras de derecho y de pensamiento político que forjaron la figura del Kronjurist a lo largo del periodo weimarés. La producción schmittiana de aquellos años se nos presentaría, entonces, como un forzado paréntesis en su labor como jurista y pensador político, por lo que sería lícito entenderlas como producciones menores, secundarias, y sobre todo leerlas fundamentalmente en clave autobiográfica, como mera literatura carcelaria, consolatoria, apologética. Claro que hay algo de todo esto, pero lo cierto es que, así entendida, esta comprensión no es sólo reduccionista, sino que perjudica en realidad el acercamiento teórico a la propia posición schmittiana que emerge, no sin ambigüedades y contradicciones internas, de la crisis de 1945 y que prepara su transición hasta su comeback como jurista en El Nomos de la Tierra (1950). En la resentida hora de la derrota, la necesaria reflexión del vencido no pasa, desde luego, por una clara confesión de culpa, ni por una decidida autocrítica de su errada aventura intelectual durante los años treinta, tanto de sus contribuciones estricamente teóricas como sus frecuentes concesiones antisemitas. Tampoco para las víctimas habrá un un recuerdo nítido, no lo olvidemos. Y pese a ello, el terreno que elige Schmitt entre 1945 y 1950 parte de un calculado intento por salvaguardar su espacio de reflexión como jurista, allí donde nadie se lo espera, desde una sobria estilización de sí mismo, desde una extraña pero consciente exposición literaria en la que resulta ciertamente difícil separar la vida y la obra. A esta doble exposición de Schmitt, pública como jurista, privada como ser humano concreto, nos acercaremos en las próximas páginas.

Para orientar debidamente esta fase del pensamiento schmittiano, me serviré de dos conceptos guía, el silencio y el espacio, que pueden ayudar quizá a entender esta transición. No creo que sean los únicos conceptos rectores, pues no son pocos los niveles de acceso codificados en el texto schmittiano. Ahora bien, en la medida en que su presencia vertebra la estilización que Schmitt hizo de sí mismo durante aquellos años, nos acercan a la estrategia que siguió para reflexionar no sólo sobre la génesis espiritual de la catástrofe y el destino alemanes, sino también sobre el punto y aparte

\footnotetext{
${ }^{14}$ Cfr. Der Schatten Gottes. Introspektionen, Tagebücher und Briefe 1921 bis 1924, G. Giesler, E. Hüsmert y W. H. Spindler (eds.), Berlín, Duncker \& Humblot, 2014.

${ }^{15}$ Cfr. Carl Schmitt Tagebücher 1930 bis 1934, W. Schuller (ed.), Berlín, Akademie Verlag, 2010. Los conocidos problemas de desciframiento de la estenografría de Gabelsberg que utilizaba Schmitt, unido a la circunstancia de que uno de los poquísimos transcriptores que pueden leerla, Hans Gebhardt, sobrepasa ya los noventa años, deja ciertamente en el aire la posibilidad de ver publicados íntegramente los diarios schmittianos que comprenden los decisivos años de 1934 a 1945 y que siguen, a la espera de ser descifrados, en el Nachlass de Düsseldorf. Agradezco al profesor Reinhard Mehring su indicación al respecto.
} 
que implicaba, para su propia teoría, el fracaso de la teología política, el fracaso también de la forma de Estado como representación de la Idea, como garante de la unidad, como única forma que garantizaba la producción de armonía entre sociedad y Estado, entre pueblo y soberano, así como la despedida del ordenamiento jurídico europeo que él había contribuido a cartografiar.

\subsection{El silencio}

La imagen del silencio es probablemente una de las claves interpretativas a las que menos se ha atendido a la hora de entender el proceder schmittiano tras $1945^{16}$. De manera incansable, Schmitt recurre a ella desde el momento en que entiende que su oficio como jurista, escritor y ensayista, tal y como venía ejerciéndolo libremente desde hacía más de treinta años, no podrá desarrollarse en adelante por los cauces habituales. El punto de inflexión que nos interesa subrayar aquí es la experiencia personal que vivió en agosto y septiembre de 1945, cuando a las pocas semanas de entregar un informe judicial fue arrestado y llevado a los campos de internamiento, de donde ya no saldría hasta un año y medio después ${ }^{17}$.

A mi modo de ver, aquella primera experiencia de censura y detención, o dicho en el lenguaje schmittiano, la transformación del enemigo en criminal condenado ${ }^{18}$, es fundamental aquí, pues le hace comprender que sus inquietudes e intenciones como jurista, por científico -racional y contrastable- que sea su tratamiento, han chocado

\footnotetext{
${ }^{16}$ A ella ha aludido F. Romero Feito, "Un diario heterodoxo: Ex captivitate salus, de Carl Schmitt", en El diario como forma de escritura y pensamiento en el mundo contemporáneo, L. P. Rodríguez Suárez y D. Pérez Chico (eds.), Zaragoza, Institución Fernando el Católico (C.S.I.C.), 2011, pp. 167-174, aquí pp. 170 s. Por lo demás, llama la atención que precisamente Álvaro d'Ors desatendiera esta decisiva categoría de interpretación en su aproximación al Glossarium (cfr. "El 'Glossarium' de Carl Schmitt", en Estudios sobre Carl Schmitt, D. Negro Pavón (coord.), Madrid, Veintiuno, 1996, pp. 17-47).

${ }^{17}$ En verano de 1945, inmerso en el procedimiento administrativo que le apartaría definitivamente de la Universidad de Berlín, Schmitt había recibido el encargo de elaborar un informe jurídico para la defensa del industrial sarrense Friedrich Flick. El informe, del que poseemos una edición en castellano (C. Schmitt, El crimen de guerra de agresión en el Derecho internacional, y el principio "nullum crimen, nulla poena sine lege", Buenos Aires, Hammurabi, 2006), realizaba una minuciosa reflexión sobre el estatus jurídico-internacional de la criminalización de la guerra de agresión. La pregunta es conocida: ¿puede determinarse que, para la Alemania anterior a 1945, la figura jurídica de la guerra de agresión estaba estipulada como un crimen de guerra, de suerte que la participación y colaboración en ella por parte de un ciudadano interesado tuvo lugar a sabiendas de que cometía un delito perseguible? Schmitt argumenta con ayuda de la irretroactividad expresada en la célebre sentencia de P.J.A. von Feuerbach fijada en el Código Penal de Baviera de 1813 y que había sido recogida en el artículo 116 de la Constitución de Weimar, que Schmitt conocía muy bien: nullum crimen, nulla poena sine praevia lege poenali, esto es, no hay ley, ni pena, sin una ley previa que defina el acto como pena, así como sin una legislación vigente que establezca dicha pena como sanción al delito cometido.

${ }^{18}$ Schmitt la recordará con resentimiento y cierto patetismo en su Glossarium: "En el verano de 1945, levanté miserablemente la voz y fui inmediatamente reducido al silencio" [G, 142].
} 
de frente no sólo con la innegable realidad militar de la victoria aliada. También suponía, en realidad, la constatación de la victoria de sus ruidosos altavoces, hijos privilegiados del progreso de la técnica moderna -"Hoy el progreso de la técnica moderna lo domina todo" [ECS, 22]-, los cuales amplifican y tergiversan el sentido de unas ideas, tesis y formulaciones que escapan inmediatamente al control de su autor y lo coaccionan, a su vez, de manera ineludible. La sabiduría de Macrobio está más viva que nunca: non possum scribere in eum qui potest proscribere [ECS 34; $\mathrm{RN}, 72-73,77]$

Schmitt, que ya había conocido de primera mano la ensordecedora potencia de los altavoces nazis que dominaron la escena de lo público desde 1933, asume ahora, confirmando y ampliando en cierto modo su decisivo análisis de la técnica moderna desarrollado en la conferencia de Barcelona ${ }^{19}$, que no va a ser muy distinto con la maquinaria técnica de los aliados: "En términos de la técnica moderna, esta experiencia puede formularse como sigue: todo aumento de sonido es una alteración de los sentidos y, en la mayoría de los casos, también un falseamiento de los sentidos", afirmará en el segundo dictamen nuremburgués [RN, 88]. En otras palabras: la constatación, en términos koselleckianos, de una infranqueable determinación formal de tipo binario, entre la Öffentlichkeit y la Innerlichkeit, entre la publicidad distorsionada que se articula en un sistema totalitario y la interioridad en la que busca expresarse el espíritu, sustenta la interesante reflexión schmittiana sobre la nueva textura de la comunicación y comunicabilidad modernas que emergen omnipresentes, desatadas y con pretensiones globales de la aceleración del mundo sufrida antes, durante y sobre todo después de la guerra: "Guárdate de todo altavoz; guárdate de todo micrófono que lleve tu voz a la falsa publicidad [falsche Öffentlichkeit]. Todo aumento de sonido es un falseador de sentido. La publicidad del mundo, he aquí la mentira del mundo" [G, 172].

Por tanto, al replantearse la necesidad de una nueva estrategia comunicativa, que evite o sortee en cierto modo la resonancia de nuestro falso eco, Schmitt reevalúa seriamente la idea según la cual ahora la única seguridad del individuo será aquella proporcionada por la intimidad y la desnudez del propio pensamiento, muy en la línea de Pascal: "Toda la dignidad del hombre se concentra en su pensamiento" [ECS, 23]. En este giro intimista, pues, la metáfora del silencio se alza como un recurrente Leitmotiv para reajustarse a los nuevos tiempos políticos en Alemania. Se trata, en efecto, de la célebre Sicherheit des Schweigens ${ }^{20}$, esto es, la potente imagen de la

\footnotetext{
${ }^{19}$ Cfr. C. Schmitt, "La era de las neutralizaciones y de las despolitizaciones", en El concepto de lo politico, Madrid, Alianza, 1991, pp. 107-122.

${ }^{20}$ La expresión Sicherheit des Schweigens ha creado escuela - pensemos, por ejemplo, en el título de la obra de D. van Laak, Gespräche in der Sicherheit des Schweigens - Carl Schmitt in der politischen Geistesgeschichte der frühen Bundesrepublik, Berlín, Akademie Verlag, 1993. Sin embargo, es importante insistir en que su atribución a Schmitt sólo puede ser rastreada indirectamente a través de las numerosas intervenciones del ayudante del fiscal Robert Kempner, interrogador de Schmitt en
} 
"seguridad del silencio", concebida como inexpugnable reducto del ser humano y de su inalienable unicidad, genuino hogar del pensamiento, garante último de su integridad y desnudez. En este extraño lugar se configura, sin embargo, un nuevo espacio de reflexión cuyo acceso depende, en último término, de nuestra capacidad y predisposición para seguir el ambiguo juego que nos propone Schmitt: seguir el movimiento de su "personalidad angular" (D’Ors), es decir, su carácter, ora enigmático y cifrado, ora irónico y sarcástico, al tiempo que entendemos, sin rechazarlo de antemano, el resentido patetismo y el amargo rencor de su consolatio moderna, innegables sentimientos del vencido que impulsan en todo momento su autocomprensión y conceptualización literarias ${ }^{21}$.

El silencio, claro está, es una potente arma de doble filo. Por un lado, pensamos en su innegable dimensión religiosa: el silencio parece inscribirse en una determinada tradición espiritual católica, a saber, aquella que hace del voto de silencio una senda necesaria de la penitencia humana. Al ejercer una suerte de poder coactivo sobre quien se lo impone, el silencio confiere pureza, desnudez, intimidad, al mismo tiempo que salvaguarda la cercanía con Dios y el secreto del origen divino del ser humano. Incluso podría interpretarse, por ejemplo, que esta desnudez de la celda, donde el ser humano desamparado descubre que el silencio permite conocerse en la identidad más íntima del Yo, tendría una dimensión fundamentalmente liberadora para el creyente, de modo que no sería desacertado asociarla también con aquellos motivos gnósticos que impregnan el pensamiento schmittiano ${ }^{22}$. Por otro lado, en un giro que es genuinamente schmittiano, el pensador político alemán sabe que el silencio ha sido y sigue siendo la mejor arma para no callar. En el fondo, si la historia del poder político lo que hace es reproducir nietzscheanamente una suerte de tensión antropológica entre el que manda y el que obedece, la historia de las ideas políticas sería aquella que reúne simultáneamente a los que callan y a los que hacen callar pues ambos tienen voz.

\footnotetext{
Núremberg, quien popularizó esta expresión en sus propios escritos. Sobre los distintos y contradictorios relatos de Kempner es indispensable la reconstrucción de Helmut Quaritsch [RN, 39-42], aunque no menos interesante resulta el sutil desenmascaramiento que hace Blumenberg en "Zwei unbekannte Schriften des Carl Schmitt", anotaciones recogidas en la sección II de materiales en Hans Blumenberg/ Carl Schmitt. Briefwechsel 1971-1978, A. Schmitz y M. Lepper (eds.), Fráncfort d. M., Suhrkamp, 2007, pp. 188-194

${ }^{21}$ En este sentido, la calculada estilización de sí mismo tras 1945 y la plena conciencia de los mecanismos adecuados para articularla hacen que la interesante distinción que ha sugerido Mehring entre un Schmitt "esotérico" y otro "exotérico" tenga cierto rendimiento teórico, ya que, como hemos defendido, lo que permanece oculto, reservado y privado nace de la constatación de que la comunicación abierta y pública del productor clásico de la ciencia jurídica ha sufrido una transformación cualitativa tras la guerra. Cfr. R. Mehring, "Friedrich Schillers ,Demetrius' - ein später Baustein zu Carl Schmitts Hitler-Bild”, en Weimarer Beiträge 53/4, 2007, pp. 559-575, aquí p. 559.

${ }_{22}$ Sobre este importante dimensión del pensamiento schmittiano, cfr. C. Bonvecchio, Il politico impossibile. Soggetto, ontologia, mito in Carl Schmitt, Turín, Giappichelli, 1990, pp. 216-220, 242-248.
} 


\begin{abstract}
Sieh Dir genau den Autor an, der schön vom Schweigen reden kann.

So lange er vom Schweigen spricht, solange nämlich schweigt er nicht ${ }^{23}$.
\end{abstract}

En otras palabras, la reflexión schmittiana sobre el silencio reproduce de nuevo el esquema amigo-enemigo. El acto de callar subraya el primado de la dialéctica amigo-enemigo, porque esta negatividad oposicional garantiza la necesidad del otro como interlocutor e interrogador, su determinación como Fragender, frente al cual decido callar. En la medida en que identificamos a nuestro enemigo como aquel que nos cuestiona y nos pone en entredicho aun en nuestra más desnuda individualidad, nos reconocemos a nosotros mismos haciendo la pregunta de índole existencial: $T u$ quis es? Esta pregunta, que tiene un carácter prioritario dentro de producción schmittiana entre 1945 y 1950, nace como un eco, esto es, brota desde el calculado enmudecimiento voluntario de quien decide no responder. Pero se trata de un gesto decisivo, pues reafirma el valor ontológico de toda dialéctica que asuma la forma de la demanda y la respuesta: sólo a través de ese gesto específicamente humano entendemos mejor la idea schmittiana de que toda palabra nueva produce historia -precisamente porque genera respuestas concretas y únicas a situaciones concretas y únicas-, al tiempo que rechaza cualquier pretensión de exclusividad sobre la verdad histórica, ya que ésta no puede configurarse como discurso sin la complicidad del otro, sea vencido o vencedor.

Es cierto que este gesto schmittiano nos aparece bajo distintos ropajes lingüísticos, ya sea adoptando, por ejemplo, la forma de un cuestionario, como el que el rector Spranger remite a Schmitt tras la llegada de los rusos, ya sea configurándose como puro interrogatorio, como en el Palacio de Justicia de Núremberg, donde asistimos sin embargo a un control absoluto de la situación, a una excesiva y autocomplaciente superioridad intelectual que el ayudante del fiscal, Robert Kempner, quizá no debería haber permitido en algunos temas clave del interrogatorio ${ }^{24}$. Y pese a ello, la configuración de la pregunta nos revela siempre al enemigo: Der Feind ist unsere eigne Frage als Gestalt, rezan los potentes versos de Theodor Däubler incorporados al final de la "Sabiduría de la celda" [ECS, 78], igual que en la importante entrada del Glossarium del 13 de febrero de 1949 [G, 217]. En ellos se esconde ciertamente un

\footnotetext{
23 "Observa atento al autor/ que del silencio tan bien habla./ Mientras del silencio hable/ mientras lo haga, no callará" [G, 194].

${ }^{24}$ Me refiero sobre todo a la desfachatez con la que Schmitt negó, en el primer interrogatorio, su antisemitismo y su implicación en cuestiones judías. Evidentemente, durante el Tercer Reich no sólo había escrito "en una ocasión que, con respecto a la teoría de los Gebiete, los teóricos judíos no tenían ninguna apreciación sobre ella" [RN, 52]. Eso era simplemente mentira. Sobre el antisemitismo de Schmitt en la posguerra, cfr. R. Gross, Carl Schmitt und die Juden. Eine deutsche Rechtslehre (ed. corregida y ampliada), Fráncfort d. M., Suhrkamp, 2005, pp. 335-381.
} 
arcanum, una clave más para descodificar algunos de los motivos literarios de este periodo de transición intelectual ${ }^{25}$.

El enemigo, por tanto, aparece despersonalizado, desfigurado, sin rasgos definidos. Su indeterminación causa miedo, angustia, inquietud, como los terribles personajes antagonistas, desdibujados y sombríos de las novelas de Franz Ka$\mathrm{fka}^{26}$; el enemigo es pura Gestalt, ha dejado de ser Begriff, es decir, ha dejado de ser conceptualizable, aprehensible, definible. Pero Schmitt añade una última coletilla: la determinación del enemigo como nuda figura es la condición de posibilidad de nuestra identidad y autodeterminación, luego también es previa a toda discursividad. Los sujetos modernos están constituidos siempre desde la autoidentificación con el enemigo, de ahí que estemos abocados a reproducir una y otra vez el carácter imprescindible del otro a fin de escapar de nuestra propia muerte, también del rostro ambiguo de la nada. Ha sido el mérito de José Luis Villacañas el señalar con exactitud lo que puede estar en juego aquí. Con él terminamos este subapartado:

No es un azar que este libro terrible de Schmitt, Glossarium, acabe con la alabanza del mundo trágico de Schiller [...] Esos seres humanos aferrados a la identidad, tal y como Schiller los mostró en La Novia de Mesina eran incapaces de metamorfosis alguna. Ellos comprobaron a su manera la verdad del verso de Däubler. Pues ellos sabían que cuando el enemigo desaparecía, ellos se quedaban a solas con su problema y entonces sólo podían sentir su identidad y su autodeterminación dándose a sí mismos muerte. Lo que no podían consentir era una recaída en la ambivalencia, en un angustioso conflicto interior que les devolviera a su rostro ambigudo de nada. El enemigo no era sino su propio problema, en una figura. $Y$ eso era tan constitutivo de su identidad como su propio problema. Por eso Schmitt habló de una maravillosa dialéctica, de una contradicción que se puede formular así: en el otro reside la identidad. Por eso no se puede prescindir de él y por eso su muerte es tan necesaria como imprescindible su vida. Su odio nos es tan necesario como nuestro amor. De

\footnotetext{
${ }^{25}$ Una primera aproximación a estos versos la ofrece J. L. Villacañas, Poder y conflicto. Ensayos sobre Carl Schmitt, Madrid, Biblioteca Nueva, 2008, pp. 185 ss. También es importante la reflexión de J. Derrida, Políticas de la amistad, Madrid, Trotta, 1998, pp. 172 ss. y 186 ss.

${ }^{26}$ Una entrada del 31 de octubre de 1947 imagina la siguiente situación: "Franz Kafka podría escribir una novela: El enemigo. Entonces se hubiera hecho visible que la indeterminación del enemigo provoca miedo (no existe otro miedo, y la esencia del miedo consiste en olfatear a un enemigo indeterminado); por el contrario, es cosa de la razón (y, en este sentido, de la alta política) determinar al enemigo (lo que implica siempre, al mismo tiempo, autodeterminación), y con la determinación termina el miedo y permanece, como mucho, el temor. ¿Pero cómo debemos arrebatar algo a la indeterminación y reconducirlo a la determinación, si ya no tenemos conceptos comunes? Forma parte de la situación de la guerra civil el que los enemigos ya no tengan conceptos comunes y cada concepto [Begriff] se convierta en un abuso [Übergriff] en el lado enemigo" [G, 36].
} 
hecho, la muerte de uno sólo podría implicar la muerte de ambos en una misma y única muerte ${ }^{27}$.

\subsection{El espacio}

Como es natural, la imagen del silencio abre también un sugerente campo de experiencias existenciales que remiten a la soledad y al aislamiento, al exilio interior, al refugio, al asilo, al encarcelamiento. Pero todas estas texturas vivenciales son derivadas de una ganancia ulterior, que es la ganancia de espacio. La experiencia de su propio tiempo adquiere ahora una dimensión espacial. No es casualidad que las oscuras palabras de Gurnemanz emerjan aquí con renovada fuerza: Zum Raum wird hier die Zeit.

Es claro que la noción de Raum representa uno de los problemas conceptuales más complejos y fascinantes de toda la obra schmittiana. El problema radica sobre todo en que se trata de un concepto en plena disolución, jamás se estabiliza y encuentra la habitual claridad conceptual que caracteriza el potente lenguaje schmittiano. Así, mientras que en el ámbito del derecho internacional el jurista había estado buceando en las peligrosas aguas de un concepto jurídico-científico de Großraum ("gran espacio", pero en cierto modo también "espacio imperial") más o menos desde 1933 -uno de los puntos clave de la acusación en Núremberg ${ }^{28}$-, el viraje de Tierra y mar (1942) reevaluaba, desde una inesperada visión cósmica impregnada de motivos gnósticos, la conformación de la conciencia espacial desde la comprensión simbólica de los elementos, condición de posibilidad para explicar el modo de concebir los ordenamientos político-jurídicos, las relaciones internacionales entre los estados y, no por último, aquella "relación-límite" (Volpi) con el enemigo que se expresa antropológicamente en el texto de la historia universal. La reflexión sobre los espacios que nos han ido constituyendo revelaba, en el lenguaje de Schmitt, que el arcanum del poder, aquel secreto que afectaba al ordenamiento del mundo, a la constitución de nuestras instituciones políticas y a la organización de toda vida humana se hacía inaccesible a nuestra comprensión mediante la mera conceptualización y categorización jurídicas o políticas. Antes bien, es la privilegiada posición de quien se encuentra retenido en el oscuro umbral, de quien, como el silenciado Benito Cereno, asiste indefenso como rehén a la deriva de un barco que es arrastrado por el maelstrom de la historia, esta arriesgada perspectiva, decimos, era la única que a ojos de Schmitt permitía el acceso a las técnicas del poder indirecto, a los misterios de los arcana imperii.

\footnotetext{
${ }^{27}$ J. L. Villacañas, op. cit., p. 187.

28 "Yo me he esforzado por fomentar y formular la clarificación de un concepto moderno de Raum con los medios y los métodos propios de mi especialidad científica", escribirá en los compases iniciales de su primer dictamen nuremburgués [RN, 68], que contestaba, a su vez, a la pregunta que Robert Kempner le había planteado al final del primer interrogatorio: “¿En qué medida impulsó usted la fundamentación teórica de la política hitleriana del Großraum?" [RN, 55].
} 
En este sentido, no me parece desacertado recordar que toda la reflexión schmittiana sobre la naturaleza de las revoluciones espaciales que se articula a partir de Tierra y mar está animada por una revisión del parágrafo 247 de los Principios de la filosofía del derecho de Hegel: "Así como la tierra, el suelo firme, es la condición para el principio de la vida familiar, así el mar es la condición para la industria, el elemento vivificante que la impulsa hacia el exterior", apuntilló Schmitt en la nota final que incorporó a la tercera edición de $1981^{29}$. Se trata, en efecto, de un punto de partida filosófico desde el que explorar, con Heidegger y Jünger, la idea según la cual "hoy no entendemos ya por espacio una simple dimensión de profundidad vacía de todo contenido imaginable. El espacio se ha convertido en campo de fuerzas donde despliega el hombre su energía, su actividad y su esfuerzo" ${ }^{30}$. En cierto modo, sugiere Schmitt, los grandes cambios de la tierra en lo geográfico, como el paso paradigmático de la Landnahme a la Seenahme, no son sino el aspecto externo, la carcasa exterior de una transformación más profunda que afecta en realidad a todas las esferas vitales por igual. Todas las formas de existencia participan siempre en el nuevo sentido espacial que irrumpe tras su conquista o colonización efectivas, generan un orden concreto, de ahí que toda revolución espacial lo sea también en un sentido trascendental, por cuanto refleja una determinada victoria de las fuerzas creadoras humanas (arte, ciencia y técnica), fieles sismógrafos de nuestra relación con el mundo. Cada mundo particular descubre, por tanto, la espacialidad del espacio que le pertenece, de ahí que se pueda afirmar que el mundo ya "no está en el espacio; por el contrario, es el espacio el que está en el mundo" ${ }^{31}$.

Ahora bien, la reflexión geofilosófica sobre el espacio incorpora tras 1945 una nueva dimensión, fruto de la experiencia personal que hemos venido esbozando desde distintas perspectivas, a la que debemos añadir, como se acaba de sugerir con la anterior cita, su atenta lectura crítica de Heidegger. Su mejor definición ha sido repetida no pocas veces: "Esta es la sabiduría de la celda. Pierdo mi tiempo y gano mi espacio" [ECS, 78], pero también existen interesantes variaciones menos conocidas, como aquella expresada en una entrada del 21 de septiembre de 1947, en la que Schmitt sostiene la naturaleza no espacial del $\operatorname{cine}^{32}$, o la entrada de mediados

\footnotetext{
${ }^{29}$ Cfr. C. Schmitt, Tierra y mar. Una reflexión sobre la historia universal, Madrid, Trotta, 2007, p. 82. Inmediatamente después, añade a modo de invitación: "Dejo al atento lector la tarea de encontrar en mis reflexiones el inicio de un intento de desarrollar este parágrafo de un modo análogo al que los parágrafos 243-246 fueron desarrollados por el marxismo".

${ }^{30}$ Ibidem, p. 80.

${ }^{31}$ Ibidem, p. 81, aunque la cita corresponde a M. Heidegger, Ser y tiempo, traducción, prólogo y notas de J. E. Rivera, Madrid, Trotta, 2006, p. 136.

32 "Para mí es deprimente y ofensiva cualquier representación teatral en el cine. Debo aparentar ver representado algo que no está presente [gegenwärtig], sino fotografiado. No son personas presentes aquellas con las que me veo confrontado. El juego [Spiel] no se produce, sino que se reproduce mecánicamente. El último teatro de marionetas es más que la mejor de las películas. Ni presencia ni representación, terrorífico, escalofriante, una devastación anímica, ocular y auditiva. Sin espacio
} 
de diciembre de ese mismo año, donde describe cómo la experiencia inaudiblemente consciente de la radio transforma el espacio que habita ${ }^{33}$, o incluso la de dos días antes, aprovechando uno de sus recurrentes dardos críticos contra Huxley y su desnaturalización de la utopía ${ }^{34}$. En todos estos casos, el denominador común es la constatación según la cual la movilización total de todas las esferas humanas propiciada por la penetración de la técnica y la industria modernas -momentos schmittianos de la neutralización de lo político- ha deslocalizado irreversiblemente las dimensiones hospitalarias del ser humano. Nuestro lugar (Ort) es ya innombrable, nuestra Ent-Ortung irreversible ${ }^{35}$. Por tanto, para Schmitt, a la vista de la confirmación del diagnóstico y pronóstico jüngerianos; a la vista también del desarraigo, desasentamiento y desterritorialización que emerge tras la guerra, la reconquista del espacio interior humano como unidad mínima, como unicidad irreductible e inalienable, como punto cero inviolable, se convierte ahora más que nunca en el dictum de quien, en la amarga y resentida hora de la derrota, se ve necesitado de un espacio privado pero visible que reflexione, entre otras cosas, sobre las causas del fracaso de su teología política, pero también sobre las razones más profundas del éxito de Hitler, conquistador espacial por partida doble: como poder absoluto y omnipresente en el espacio público y político alemán, pero también como huésped extraño, como tenebrosa idea que se apodera del espacio interior del individuo y hace público lo que debiera permanecer en secreto.

La ontología emigra ahora hacia la interioridad de una nueva y reasentada conciencia espacial, se convierte en una suerte de topología interior. En el Glossarium encontramos numerosos atributos: el espacio es acontecimiento (Ereignis), propiedad (Eigentum), presencia (Präsenz) o poder presente (präsente Macht). Y como es habitual en el Schmitt más católico, esta naturaleza espacial del ser implicará ponerla

\footnotetext{
incluso se suprime el espectador, que ya ni siquiera puede aplaudir razonablemente; los habitantes de la caverna del cine, expresión de su vegetar subterráneo. Espacio = Presencia. Esta es la reflexión por la que desde hace 10 años no me es posible visitar un cine y ver una película. Con ello me alejo de la realidad de mi tiempo; pierdo mi tiempo y gano mi espacio" [G, 16].

33 "Yo pierdo mi tiempo y gano mi espacio. Sin embargo, tan pronto como digo esto, resuena un tecleo de piano en la radio de al lado y me enseña que un espacio atravesado por ondas extrañas ha sido destruido como espacio propio. De las inaudibles ondas que giran alrededor de mi espacio no soy ciertamente consciente en cuanto que son audibles, aunque sí en cuanto que son inaudibles" [G, 60].

34 "Yo pierdo mi tiempo y gano mi espacio. Time must have a stop. ¡Fuera con los 1800, por mí con los 18.000 años! ¡Terminemos con la utopía! Aldous Huxley cierra la época de la utopía, Tomás Moro la inauguró. Él ahora puede ser santificado, mientras que Huxley (a people) can only be condemned out of its own mouth" [G, 60].

${ }^{35}$ Sobre este punto, cfr. E. Ocaña, "Carl Schmitt: Topología de la técnica”, en Daimon. Revista Internacional de Filosofía 13, 1996, pp. 21-40, esp. p. 34 ss. Una reactualización de este debate desde una perspectiva menos filosófica y más cercana a la teoría política la ha ofrecido recientemente G. Tripolone, "La relación entre derecho, técnica y guerra en el pensamiento de Carl Schmitt", en Daimon. Revista Internacional de Filosofia 65, 2015, pp. 93-105.
} 
en relación con aquella otra seguridad y protección que proporciona el propio lenguaje materno: "me sobreviene la tranquilidad que guarda el sentido de las palabras. Raum y Rom es la misma palabra. Es magnífica la fuerza espacial de la lengua alemana" [ECS, 78]. De hecho, es la misma fuerza que hace que en alemán rimen la palabra y el lugar (Wort und Ort), que provoca, a su vez, que la rima y el espacio (Reim und Raum) estén intrínsecamente unidos.

En realidad, el catolicismo de Schmitt nunca estaría tan vivo como ahora. Es cierto que esta reconquista de su estatuto como cristiano, como Epimeteo cristiano, puede obedecer a una calculada estrategia personal. La huída a lo religioso, la instrumentalización del cristianismo se convirtió en un habitual mecanismo de defensa de no pocos intelectuales tras la posguerra, a fin de sortear numerosas acusaciones de orden moral, por ejemplo en su relación con el antisemitismo ${ }^{36}$. Pero decir que la dimensión cristiana que se expresa en la reflexión schmittiana se reduce a eso es igualmente equívoco: la defensa de la interioridad del espacio humano, aunque sea en términos católicos, enlaza directamente con una reflexión más integral sobre la innegable aceleración del mundo sufrida durante la guerra y el aspecto escatológico que de ella se deriva. En efecto, el Raum como Rom no es un eco estéril, un simple juego de palabras, sino otra forma de invocar indirectamente el kat-echon, la fuerza retenedora. Frente a la aceleración del tiempo, conquista del espacio, generación de orden y producción de derecho, dando así sentido, en última instancia, a las formas políticas. Por tanto, si la preferencia de Carl Schmitt por el espacio refleja su concepto de orden concreto, su respuesta católica a un problema estrictamente moderno puede ser considerada como una reactualización necesaria de la terrible pregunta de san Jerónimo: quid salvum est, si Roma perit?

Ha llegado el momento de interrumpir nuestras pinceladas orientativas sobre la producción schmittiana que emerge de la crisis de 1945. Hemos reconstruido algunas de sus piezas y etapas, hemos identificado algunas de sus claves interpretativas, de modo que confieran cierta unidad a una época de transición de su pensamiento que, dada la naturaleza poliédrica de los textos que la componen, dificulta un acercamiento más sistemático. Armados con estas herramientas de trabajo, podemos acercarnos con algo más de seguridad a "Berlín, 1907".

\section{Luces y sombras en el theatrum mundi berlinés: de la universidad guillermina al problema del genialismo}

En 1907, un joven estudiante católico de la tranquila región moselana es arrastrado por una fuerte e inexplicable corriente que lo arroja a las aguas pantanosas

\footnotetext{
${ }^{36}$ Sobre este punto, cfr. R. Gross, op. cit., pp. 335-340.
} 
del Berlín guillermino. Así empieza el relato de juventud de Carl Schmitt, con una sugerente invitación a pensar seriamente la identidad más íntima de aquellos ríos que atraviesan la geografía alemana. Por un lado, el Mosela, aquel río comentado ya por Tácito, dignificado luego por Ausonio en sus famosos hexámetros, esto es, un río romano, un río católico, por cuanto la región vitícola que ha bañado con sus aguas ha simbolizado históricamente el feudo clásico de la religión apostólica en el territorio alemán. Este fue siempre el río de Schmitt: "Mi naturaleza es sosegada, silenciosa y complaciente, como un río tranquilo, como el Mosela, tacito rumore Mosella" [ECS, 26], citando de nuevo el viaje ausoniano. Por el otro, en una suerte de contrapunto literario altamente estilizado, la metáfora del maelstrom de Poe -debidamente recuperada y reinterpretada por Jünger partiendo del diagnóstico nihilista en la edad de la técnica-, aquel ingente remolino que a partir de la época guillermina arrastró a buena parte de la generación de Schmitt hacia la atractiva capital del Reich.

Durante cuarenta años, una fuerte corriente me ha lanzado una y otra vez del oeste de Alemania a Berlín, deteniéndome allí hasta hoy, en contra de todos mis instintos y simpatías, de todos mis planes y proyectos. Desde hace dieciocho años tengo mi domicilio en Berlín, sin quererlo demasiado y sin lograr remediarlo. A muchos alemanes de mi época y de mi estrato social les ha pasado lo mismo. Una turbina gigantesca nos atrajo. Una tromba nos ha dejado aquí. Berlín fue nuestro sino, y nosotros, las víctimas, fuimos el sino de Berlín [ECS, 43].

Dejando de lado su lamentable y resentida autoidentificación como víctima, lo decisivo aquí es subrayar no sólo la importancia de la contraposición estética entre la pureza simbólica del paisaje westfaliano y la crudeza de la metrópolis moderna, esto es, la construcción y la defensa de un imaginario colectivo del catolicismo alemán que evoque su fuerza retenedora frente a la disolución de los grandes paisajes espirituales del país ${ }^{37}$, sino también el carácter fatídico de su desembocadura nihilista, un nihilismo que no es sino una representación vacía de contenido arrastrada por la

\footnotetext{
${ }^{37}$ Aunque subsumido en el análisis de la complexio oppositorum, este imaginario colectivo está presente ya en Catolicismo romano y forma política (1923), concretamente en uno de los pasajes donde mejor se aprecia el diálogo con el Weber de 1905: "Parece que los pueblos católicos tienen una relación con el suelo distinta de la que tienen los protestantes; [...] Los pueblos católico-romanos parece que aman de otro modo el suelo de sus raíces, la tierra materna; tienen todos ellos su terrisme. La naturaleza no significa para ellos lo contrapuesto a lo artificial y a la obra del hombre, como tampoco a lo racional o sentimental o al corazón, sino que el trabajo humano y el crecimiento orgánico, la naturaleza y la razón, son la misma cosa. El cultivo del vino es el símbolo más hermoso de esta fusión, pero hasta las ciudades construidas a partir de ese tipo de espíritu parecen productos crecidos naturalmente del suelo, que se integran al paisaje y permanecen fieles a su tierra. La esencia de su concepto de lo urbano extraña una humanidad que sigue perpetuamente inaccesible al mecanismo de precisión típico de una moderna ciudad industrial" (cfr. C. Schmitt, Catolicismo romano y forma política, estudio preliminar de R. Campderrich Bravo, traducción y notas de P. Madrigal, Madrid, Tecnos, 2011, pp. 12 s.).
} 
irrefrenable turbina del maelstrom de la historia. Berlín fue ciertamente el destino de muchos alemanes, incluido el de Schmitt; para otros muchos, además, un infierno y un crematorio, la tumba definitiva de los nuevos hijos de Prometeo $^{38}$.

Esta es, desde luego, la comprensión schmittiana a partir de 1945. Ahora bien, ¿cómo se ha llegado a semejante situación? ¿Cómo ha sido posible? Lo brillante de la aproximación de "Berlín, 1907" estriba en el hecho de esbozar retratos, intuir formas, plantear texturas socioculturales desde las cuales entender aquella importante transición que tuvo lugar en la propia autocomprensión de la Kultur alemana a principios del siglo xx. Ese es el tema del escrito, primero: la constatación del final de la antigua Bildung ilustrada y el abandono de la irónica y en cierto modo goetheana autocomprensión de la propia subjetividad genialística como praxis por la que un individuo se apropia de una determinada tradición y hace su experiencia vital, como formación del sujeto moderno en tanto trabajo de sí mismo. Segundo: que dicho final ha desembocado en una nueva versión del theatrum mundi repleto de histriónicas máscaras. O dicho con más claridad: en una peligrosa degeneración pseudorromántica de "las distintas formas representativas del Yo", donde la primacía de una Bildung eminentemente estética promueve y desata, con su ilusión de autosuficiencia, una suerte de hiperindividualismo que propugna unos nuevos ideales heroicos que alejan violentamente al sujeto del horizonte normativo que abarcaba la antigua Kultur; un grio que proyecta un delirio del Yo que se materializa en un nuevo concepto de genio, pura creatividad y desbordante personalidad donde este percibe el triunfo de su potencia subjetiva -la potencia infinita del Yo apropiador-y la irradiación de su poder mediante el propio sentimiento de plenitud. Nos encontramos, así me lo parece, en el punto de inflexión de la ästhetische Ermächtigung (Hebekus), de aquel empoderamiento estético que vació de contenido el horizonte normativo de una generación en detrimento de la pura realidad efectiva de lo ficcional ${ }^{39}$.

En este sentido, la transformación del concepto de Genialismus, probablemente uno de los legados menos atendidos de Otto Weininger ${ }^{40}$, adquiere para Schmitt una importancia crucial, ya que en él se opera el paso decisivo que va de la consideración particular de la obra de un genio al proceso omniabarcante de armonización estética

\footnotetext{
38 "En realidad, para muchos de sus habitantes no significaba más que un lugar de agitado trabajo, con buenos teatros y mucha vida nocturna, soportable gracias a los frecuentes viajes al mar o a la montaña; un hormiguero ávido de novedades, un horno prometeico y, finalmente, un crematorio. Desde el punto de vista histórico, ¿era en definitiva algo más que un crematorio o, al final, ni siquiera esto, sino un cajón de basuras y una escombrera?" [ECS, 43].

${ }^{39} \mathrm{La}$ inevitabilidad de las ficciones, su valor práctico y su carácter orientativo era un tema que ya había sido abordado por el joven doctorando en su época de Estrasburgo, cfr. C. Schmitt, "Juristische Fiktionen", en Deutsche Juristen-Zeitung XVIII, 1913, col. 804 ss.; "Richard Wagner und eine neue, Lehre vom Wahn'”, en Bayreuther Blätter 35, 1912, p. 239 ss.

${ }^{40}$ Sobre la temprana influencia de Weininger en el joven Schmitt, cfr. la introducción de los editores en Carl Schmitt. Die Militärzeit 1915 bis 1919..., op. cit., pp. 4 ss.
} 
que desencadena. Lo que resulta interesante del genio ya no puede ser la obra propiamente dicha, sino el efecto entusiástico que el individuo genial provoca sobre la sensibilidad formativa de las identidades colectivas de una determinada generación. "Al final, sólo quedaron los efectos desde la cátedra", dirá con amargura Schmitt al descubrir la pura mascarada de una Bildung humanista que sólo sabe escudarse en el Fausto: "La máscara goetheana fue la peor desgracia de la época. Con ella se les inoculó a miles de jóvenes entusiastas la ilusión de una potestas spiritualis", mientras que la noble religión goetheana de la burguesía ilustrada, que para Troeltsch, Spranger o Popitz todavía había sido defendida encarecidamente como tercera vía, como tercera religión, mostraba en realidad su incapacidad a la hora de entender que el futuro no pasaba ya por la defensa de una Bildungsreligion excesivamente optimista ${ }^{41}$.

Para entender lo que está en juego, es indispensable remitirse a una entrada de mayo de 1948 que ilustra perfectamente el viraje estético ocurrido durante el fin de siècle alemán: "El paso decisivo alrededor de 1900 fue la transición del genialismo goetheano al hölderliniano" [G, 151]. En otras palabras, el genialismo optimista, irónico y neutralizador à la Goethe deja paso a un genialismo pesimista, activo y ciertamente trágico, de impronta innegablemente hölderliniana. Una generación entera que se alinea con "Hölderlin contra Goethe" (Hellingrath), una "juventud sin Goethe" (Kommerell) se convierte en abanderada de una irresponsable celebración del egotismo, de un nuevo culto al genio que nada quiere saber de límites, cuya naturaleza trágica, heroica y secreta contrasta con la imagen pública, visible e irónica de quien ofreció, sin embargo, una serie de prestaciones culturales adecuadas. "Todos son genios", anotaba en su diario en diciembre de 1947, "el concepto de genio, la gran desgracia" [G, 57], das große Unheil.

Es sabido que la base teórica de toda esta reflexión sobre la productividad del genio ya había sido desarrollada en Romanticismo político (1919): la producción desatada del genio romántico y la genialidad divina eran definidas en aquel temprano escrito como una nueva forma de subjetividad incapaz de autocomprenderse, en la que "el sujeto genial que crea una obra de arte es identificado con Dios, que crea el mundo" "2. El sujeto romántico, que Schmitt identifica como sujeto social histórico claramente determinado - la nueva burguesía-, sólo sabe de sí en el acto de crear, es pura actividad que se realiza en la imaginación productiva que él sabe de sí mismo. Por tanto, la hegemonía del arte, al operar con una fuerza omniproductiva que, al representarse intelectualmente a sí misma, aspira a producir el todo como universalidad lógica y ontológica, logra colonizar todas y cada una de las esferas del quehacer humano, empezando por el propio lenguaje, y propicia el posterior trasvase de lo

\footnotetext{
${ }^{41}$ Sobre la Bildungsreligion goetheana y la línea protestante que va de Troeltsch a Popitz es interesante la reflexión, cargada de nostalgia y cierta tristeza, del viejo jurista en 1971, cfr. C. Schmitt, "Solange das Imperium ..., op. cit., pp. 96 s. y nota (p. 175 ss.).

${ }^{42}$ C. Schmitt, Politische Romantik, Berlín, Duncker \& Humblot, 1998, p. 108.
} 
estético sobre la acción y las prácticas políticas concretas. O dicho con mayor rigor: sobre el acto o gesto vital en que se realiza o materializa la especificidad de toda acción y práctica políticas, a saber, la pura decisión. Ahora, casi treinta años después, el análisis del empoderamiento estético se completa con el desenlace de aquel diagnóstico de 1919, aunque para ello se remontaba, contra todo pronóstico, a una de sus principales causas en el Berlín de la época guillermina.

\section{Kohler y Wilamowitz: Dos tipos burgueses, dos máscaras goetheanas}

Desde esta importante tesis de fondo, los numerosos acentos tragicómicos de los dos retratados en "Berlín, 1907" ya no resultan casuales. De la parodia a la tragedia hay siempre un pequeño paso, justamente el que marca la fatídica transición entre dos momentos históricos decisivos de la Kultur alemana. "Tras las máscaras y disfraces de la escena teatral se vislumbra una realidad histórica temible", afirmará pocos años después en aquel ensayo que reevaluaba, como ya hiciera Achim von Arnim, la permeabilidad entre la política jacobina y el Hamlet shakespeariano $0^{43}$, la permeabilidad entre mito e historia. Aquí ocurría algo parecido. En efecto, los dos tipos que entran en escena, las dos máscaras del Yo burgués que tanto impactan al joven estudiante, se le aparecen al Schmitt de 1945/46 como un imprescindible sedimento cultural para explicar buena parte de lo sucedido en su propia generación: para dar cuenta, como antes señalado, del delirio y la angustia colectivos, de la Lagerpsychose y de la obsesión narcisista y enfermiza con el Yo que el jurista observa a diario en el campamento americano. No lo olvidemos: la representación teatral a la que asistimos se escribe siempre desde el umbral del presente, su observador, una suerte de renovado Larvatus prodeo, continúa siendo el mismo espectador de 1907, apartado, alejado, más cerca de las sombras -l'obscurité protège mieux- que de los focos del teatro, pero sus actores enmascarados, aquellas distintas formas representativas de la creencia en el Yo, esconden en el fondo el mismo rostro burgués: las máscaras del gran teatro berlinés protagonizan ahora el último acto, un acto patético, lamentable, redundante que reproduce de nuevo los patrones de comportamiento de las figuras histriónicas que representaron el primero de sus actos. Parece difícil pensar que Brecht, un atento de lector de Schmitt, no hubiese disfrutado con este texto.

Del retrato de Josef Kohler (1849-1919) sobresalen, en un primer nivel de análisis, los acentos cómicos y caricaturescos de su naturaleza pretendidamente fáustica. Schmitt, que en el semestre de invierno de 1907/08 asistirá tanto a su clase magistral "Introducción a la ciencia del derecho" (Einführung in die Rechtswissenschaft) como a sus correspondientes prácticas ${ }^{44}$, recuerda con punzante precisión su sem-

\footnotetext{
${ }^{43}$ Cfr. C. Schmitt, Hamlet o Hécuba. La irrupción del tiempo en el drama, Valencia, Pre-Textos, 1993, p. 17.

${ }^{44}$ Cfr. R. Mehring, op. cit., p. 24.
} 
blante barroco, su dandismo, su vanidad, sus geniales ocurrencias. Su inolvidable aspecto y el imparable torrente de sus ideas, al contrastar diametralmente con la asepsis del objeto de estudio que enseñaba, al distorsionar con irreverencia lo que se esperaba de alguien en su posición, acercaba y seducía a numerosos jóvenes que no podían sino ceder ante aquella proyección genial de su individualidad. En vez de la aridez memorística de la ciencia del derecho, "de los callejones sin salida del positivismo jurídico estatal y del acervo material de los historiadores del derecho", el polifacético Kohler era "el único que hablaba de Hegel y Bachofen y que parecía abrimos una ventana al vasto mundo". Este matiz me parece importante: por muy esperpénticas y grotescas que sean nuestras máscaras, por muy histriónica que sea nuestra publicidad, todo ello es secundario si la ganancia también es sincera y sustancial. La traición al maestro nunca es plena. En este sentido, Schmitt no esconde su agradecimiento a quienes acompañaron su camino formativo: "A ellos, como a algunos otros profesores de Berlín, les estoy obligado a la gratitud"

Ahora bien, en un segundo nivel de análisis, Schmitt pasa de lo externo a lo interno, de la Öffentlichkeit a la Innerlichkeit. No es otro el lugar en el que buscar algunas de las incongruencias y contradicciones de aquella generación de mandarines, intelectuales y artistas alemanes, portadores de nuevas y seductoras máscaras, que vivieron la irrupción cultural de Nietzsche, la confirmación de Schopenhauer o la victoria estético-musical de Wagner. Kohler encarna perfectamente una nueva libertad de artista dentro del propio mandarinato alemán, entre los "prohombres y arribistas berlineses", pero sobre todo representa una mezcla explosiva y desatada de inquietudes e intereses espirituales, así como un desbarajuste formativo de tal calibre que, para Schmitt, "se ha convertido en el primer ejemplo en carne y hueso de la confusión que el delirio del Yo y el concepto de genio han causado en la Bildung alemana".

En efecto, cuando leemos afirmaciones no exentas de mordacidad, como por ejemplo que "lo único decisivo era que nada sobrepasara a su propio Yo", o que "no podía pensar ni decir nada sin remitirse para ello a sí mismo, sin explicarse,

\footnotetext{
${ }^{45}$ En el caso de Kohler, no me parece desacertado afirmar que despertó su interés por Shakespeare, cuya original aproximación histórico-jurídica en su exitoso Shakespeare ante el foro de la jurisprudencia (1883) conocía muy bien (cfr. Hamlet o Hécuba, op. cit., p. 13 y n. 1 (p. 57)). Kohler había desarrollado en el tercer capítulo de este libro dos temas hamletianos que acompañan también la investigación del propio Schmitt: por un lado, el problema de la complicidad de la madre en el asesinato del rey, por el otro, más importante para Kohler, el tema de la venganza de sangre y, sobre todo, el enfoque desde el que éste puede ser presentado. Recordemos que Schmitt cargará aquí contra todas aquellas "investigación psicológicas, filológicas e histórico-jurídicas" (p. 13), así como contra aquellas explicaciones "psicoanalíticas con sus complejos relativos al padre o a la madre" (p. 14), con el fin de defender una comprensión del mito y de la figura de Hamlet que refleje en última instancia la escisión trágica, el desgarramiento fatídico de la unidad política y espiritual europeas -el nomos de la tierra-, cuyo punto de inflexión Schmitt localiza históricamente en la época de los Estuardo. En el caso de Wilamowitz, Schmitt tampoco escondió el diálogo crítico con alguna de sus ideas, por ejemplo con respecto a la tragedia ática (cfr. de nuevo Hamlet o Hécuba, op. cit., p. 38 y n. 20 (p. 61)).
} 
representarse a sí mismo o incluir a su Yo en todo lo que pensaba y decía", Schmitt no sólo está proyectando - con una buena dosis de cinismo, basta pensar en su pasado libertino y de bon vivant- uno de sus miedos más profundos como católico, a saber, la ocassio peccati del amor de sí (Selbstliebe) y la soberbia (Hochmut) causados por una desaforada reproducción literaria del $\mathrm{Yo}^{46}$. Creo, también, que contienen un resabio agridulce, por cuanto contrastan con aquel ideal formativo, ascético y protestante que Schmitt hubiera deseado conocer en Heidelberg, como bien señala en los primeros compases de su relato. Desde luego, la anhelada figura del profesor Max Weber emerge y se difumina rápidamente en el marco de las llamadas ucronías, aquellas peligrosas e "irreales oraciones condicionales". Sin embargo, al mismo tiempo, nos es imposible borrarla del todo: Weber es él último receptor e intérprete del ambiguo mensaje fáustico, y como tal entendió perfectamente el destino espiritual que se jugaba en las propias universidades alemanas cuando lo expresó en Wissenschaft als Beruf, aquella imborrable conferencia muniquesa de 1917 a la que, por cierto, asistió el propio Schmitt: "el profeta y demagogo no pertenecen a una catedra de un aula".

En este sentido, no es casualidad que la novela de Kohler titulada Una naturaleza fáustica, que salió a la luz aquel mismo año de 1907, se sitúe estratégicamente en el centro del retrato, en uno de los pasajes más sarcásticos que jamás haya escrito Schmitt. No es para menos. Se trata, en su opinión, de una de las degeneraciones más patéticas del Bildungsroman de signo goetheano, un alarmante síntoma del delirio narcisista dentro de la propia intelectualidad alemana, que hace de la sutil e irónica (auto)comprensión goetheana de todo recorrido formativo un esperpéntico camino plagado de autosatisfechos superhombres y de un soportable nihilismo, de Liebestod wagneriano, de pseudotragedias burguesas, todo ello redondeado, para mayor escarnio, por la optimista creencia de que la innegable genialidad de su protagonista será recompensada por una cátedra universitaria. El Estado siempre proveerá. "El héroe se recupera en un viaje por Italia mediante la contemplación artística y finalmente aparece el Ministerio de Cultura prusiano con el llamamiento a Berlín, como la reina de las hadas en un país de las maravillas para eruditos geniales y su Yo más primordial". Una naturaleza fáustica es, en definitiva, una novela sintomática, con un protagonista kierkegaardianamente cómico que ha diluido su soledad heroica en el baño narcisista de la experiencia estética. En su texto podemos leer los gestos y aspavientos de un culto goetheano ya degenerado, que es incapaz no sólo -pues eso sería pedir demasiado- de acercarse a narrar el abismo de lo verdaderamente trágico,

\footnotetext{
${ }^{46}$ Me baso aquí en la entrada del 10 de septiembre de 1947 [G, 13], que recoge el voto del cardenal Passionei de 1753 sobre el que se fundamenta la posición de Schmitt. También ECS explora esta dirección: "Un jurista que se ha educado a sí mismo y a otros muchos para la objetividad evita narcisismos psicológicos. Los odiosos ejemplos de Jean-Jacques Rousseau y del pobre August Strindberg me han quitado la inclinación a declaraciones y confesiones literarias [...] Quien quiera confesarse, vaya y muéstrese al cura" [ECS, 68].
} 
sino incluso de plasmar desde una saludable y consciente autoironía la ambigüedad constitutiva de todo camino formativo.

El retrato de Ulrich von Wilamowitz-Moellendorff (1848-1931) tiene otros matices muy interesantes que no quisiera dejar de subrayar. En su primer semestre de verano, el joven Schmitt asistió a su clase magistral Kultur des Hellenismus, y parece difícil no creerle cuando describe con qué admiración y respeto vivió al principio sus espectaculares conferencias. El filólogo clásico era una verdadera autoridad académica en el punto álgido de su carrera, pura erudición, finísima elocuencia, aristocracia en las formas; encarnaba el triunfo burgués -y prusiano- de la Bildung alemana y su horizonte normativo, precisamente aquella versión de la Bildung humanística que el joven Nietzsche criticó desde distintos frentes en su época de Basilea y que el joven delfín Wilamowitz, a su vez, no dudó en aplastar con inusitada dureza y ortodoxia filológica $^{47}$. El resultado es conocido. La victoria y el ascenso meteórico del segundo y la derrota y el ostracismo al que fue condenado el primero confirmaban el triunfo de un modelo educativo autosatisfecho, burgués y prusiano, aquel que garantizaba la formación del "tipo de hombre moderno alemán". Como en el caso de Kohler, explica Schmitt, la vestimenta con que adornan su "optimismo panteístico" está hecha con el mismo material de la cultura alemana, a saber: la interpretación moderna del Fausto. La obra goetheana se convierte así en un cajón de sastre cultural que proyecta, una y otra vez, rellenándola de una retórica ética vacía y efectista, la propia autosatisfacción burguesa de quien lanza miradas complacientes a la Antigüedad clásica. "También yo puedo citar al Mefistófeles", escribía con sarcasmo el prometedor filólogo en 1872, con ocasión de las supuestas verdades eternas de lo apolíneo y dionisíaco que había enunciado el joven Nietzsche ${ }^{48}$. En efecto, nunca dejaría de hacerlo.

Ahora bien, a diferencia de Kohler, los argumentos que utiliza Schmitt para explicar la profunda y repentina decepción que sintió con el célebre helenista son bastante más sutiles, y no me parece desacertado señalar que la clave para entenderlos la ofrece el propio Schmitt en la medida en que remite, con ocasión de la figura de Cicerón, al concepto de "guerra civil" "49. En efecto, la guerra civil es la madre de todas las

\footnotetext{
${ }^{47}$ Cfr. U. v. Wilamowitz-Moellendorff, “¡Filología del futuro!”, en F. Nietzsche, Obras Completas I: Escritos de juventud, traducción, introducción y notas de J. B. Llinares, D. Sánchez Meca y L. E. de Santiago Guervós, Madrid, Tecnos, 2010, pp. 897-916.

${ }^{48}$ Ibidem, p. 901.

${ }^{49}$ No es recurso que deba sorprender. También en el segundo dictamen en Núremberg recurrirá a la idea de "guerra civil" como condición de posibilidad del pensamiento político más genuino (y arriesgado): "En tiempos de calma y seguridad, a los autores de tales áreas temáticas se les tolera también una libertad de pensamiento más generosa y una superioridad muy elevada frente a la pregunta de las eventuales repercusiones de sus opiniones. En tiempos de una guerra civil abierta o latente, existe el peligro de que cualquier palabra pública y sincera termine de inmediato sobre el plano de los lemas propagandísticos rápidamente cambiantes y en el caos de los conceptos destruidos por el nihilismo. En este sentido he adquirido una gran experiencia y he pagado por ello mi precio. Es la misma experiencia
} 
cosas: condición de posibilidad del Estado, de su creación por parte del soberano a partir de una decisión suspendida en el estado de excepción; ella revela la dicotomía amigo-enemigo, acelera la creación de orden allí donde no lo hay. Por tanto, a la vista de esta suerte de constante antropológica fundamental, Schmitt se pregunta:

¿Qué podía saber un hombre tan bien situado, tan contenido y acomodado como este consejero secreto berlinés del año 1907 sobre un orador político, cuya existencia toda se encuentra, en cada palabra suya y en cada acontecimiento que vivió, hasta en los detalles de su muerte y de su tratamiento mortuorio, en una completa situación de guerra civil? El gran erudito, el mismo que hablaba de un modo benévolamente liberal sobre 1848 y de manera elogiosa sobre Cicerón, jamás había estado un solo segundo de su vida en el peligro en que Cicerón lo estuvo la suya entera. Jamás había caído en aquel ámbito más allá de las líneas amigas. A cualquiera, empezando por el gran erudito, le habría parecido inconcebible que su nombre se encontrara en una lista de proscritos o que él mismo estuviese proscrito y fuera del derecho.

Contra todo pronóstico, la decepción con Wilamowitz acaba siendo más profunda que con Kohler. Y quizá debiéramos indagar el porqué:

Al final, la inconsistencia existencial entre la situación de un catedrático liberal-conservador berlinés de 1907 y la de un adversario político de Catilina, Julio César y Marco Antonio hizo que la retórica áulica del primero terminase pareciéndome vacía y enmascarada. La máscara más distinguida me entristeció más que el aspecto tosco del otro erudito, que presumía de ser tan genial.

Mi hipótesis al respecto pasa por reevaluar seriamente la función instrumental o estratégica que Schmitt otorga aquí al año 1848 como chiffre y punto de inflexión negativo de la historia alemana y europea. Para ello es preciso, creo, subrayar con fuerza la "inconsistencia existencial" que encarna Wilamowitz, esto es, su incapacidad para comprender hasta que punto el carácter retórico y vacío de su contención ética se engarzaría en el discurso hegemónico del liberalismo y de su horizonte normativo, el discurso también del progreso económico y material y el optimismo histórico burgués, $y$, por tanto -al no fundamentarse en una situación histórica concreta, vivida-, invalidaría todo acercamiento a un momento existencial de profundas consecuencias para Alemania y Europa. En definitiva, Wilamowitz no había vivido la guerra civil, desconocía por completo el miedo, mejor aún, el miedo a la muerte que este conflicto invocaba, pero se atrevía a defenderlo con razones de justicia moral. Para cuadrar su argumento, Schmitt recurre a una interesante comparación: "Sobre estas experien-

que, en su época, durante las guerras europeas y civiles del siglo XvI, hicieron también los fundadores de mi disciplina, Thomas Hobbes y Jean Bodin" [RN, 88]. 
cias de la guerra civil sabía probablemente menos incluso que Theodor Mommsen, quien había conservado intensos recuerdos de 1848 y había participado en el conflicto constitucional prusiano de 1862-65". Aunque quizá deba reformularse en la nuda terminología schmittiana: quien no ha conocido el conflicto como elemento constituyente de la política, no sólo desconoce en su esencia la noción de poder, sino sobre todo la relación amigo-enemigo como contexto insuperable de lo político.

A nadie se le escapa, por lo demás, la sombra alargada de Donoso Cortés y la experiencia vivida durante el Vormärz y la revolución de 1848. Para él fue un primer aviso de la irrupción del mal, de la impotencia del liberalismo y el parlamentarismo decimonónicos, de la escisión entre legalidad y legitimidad, de la necesidad de orden en un tiempo amenazado por la catástrofe, pero también la constatación de que la época moderna, que había hecho del hombre el centro del sentido, se reivindicaba más que nunca en su creencia en el pronombre personal "Yo". Schmitt reconoce esta importante deuda en una temprana entrada de septiembre de 1947, en la que anota impresiones positivas de la correspondencia de Donoso en los últimos años en París, y con ello nos ayuda, por fin, a cerrar este estudio, ya que nos señala al último protagonista que debemos descodificar: "Impresionante [...] Le Moi est satanique par sa nature et insociable par son caractère. Dans l'enfer il n'y a pas d'autre pronom que $m o i$. Esto sería una bonita ilustración al Único y su propiedad de Stirner. Esto ya lo sabía inconscientemente en el año 1908, pero entre 1905 y 1907 se hallaba confundido por la filosofía del Yo de la Bildungstradition alemana" [G, 21].

\section{Epílogo - "Pobre Max"}

Reevaluar la importancia de 1848 no significa, por tanto, volver a subrayar sólo la conocida posición schmittiana con respecto a las funestas consecuencias espirituales del idealismo hegeliano y de la teología alemana, condensadas ya, por ejemplo, en la certera mirada del Bruno Bauer de Die bürgerliche Revolution in Deutschland. Es igual de necesario ampliar la ecuación a partir del Themenkomplex Max Stirner, cuya enigmática figura emerge, de un modo casi inesperado, en los últimos compases de "Berlín, 1907".

Así que me quedé fuera. Yo tomé mi camino y tuve que ver cómo me las arreglaba. En ello me encontré primero con un joven compañero de oficio alemán que me pareció, después de aquellos dos catedráticos, verdaderamente refrescante: Max Stirner.

Carl Schmitt conocía muy bien a Max Stirner desde sus últimos años en el internado católico de Attendorn. Como muchos de sus compañeros, el colegial sufrió de lleno el impacto editorial del llamado Stirnerjahr en $1906^{50}$. Stirner era "refres-

\footnotetext{
${ }^{50}$ Importante aquí el trabajo de B. A. Laska, Ein heimlicher Tipp. 150 Jahre Stirners „,Einziger”. Eine
} 
cante", no sólo porque entre los jóvenes alemanes estaba de moda leer El único y su propiedad, sino porque lo que tenía que decir aquel bohemio avant la lettre, aquel "heraldo de la subjetividad" [G, 84], avanzaba y preparaba, según el sentir general de aquella generación, la crítica radical de la cultura y el diagnóstico nihilista de un Nietzsche también en pleno ascenso. En la medida en que impugna el sistema hegeliano, rechazando, por ejemplo, el imperio de lo universal abstracto, el Yo de Stirner, como ha señalado acertadamente Jorge Dotti, quien ha explorado con rigor esta línea de encuentro Schmitt/Schmidt (nombre verdadero de Stirner), "aspira a estar desnudo porque propugna la liberación de todas las ataduras religiosas, morales, políticas, y la irrestricta expansión de la corporeidad vital, única verdad y realidad, sin obedecer más que a sus pulsiones y anhelos utilitarios"s1.

Con todo, la aparición final de Stirner es más que decisiva en "Berlín, 1907", porque con ella se despeja, siguiendo nuevamente a Dotti $^{52}$, la variable definitiva para entender la insistencia con que Schmitt ha explorado desde distintos accesos la problemática moderna del Yo, también el problema del genio y el genialismo, es decir, el problema del individualismo y la producción desatada de subjetividad. El círculo se cierra, porque con Stirner se identifica no sólo un paradigmático precursor de la errada figura del genio en el siglo XIX, sino sobre todo, en última instancia, al defensor radical de la inmanencia extrema y del utilitarismo solipsista. En su filosofía se revela la potencia infinita del Yo apropiador, es decir, la subjetividad que no somete su actividad creativa a otro criterio que no sea el de la utilidad y el interés más personal y más propio. El Yo stirneriano lleva la secularización y el individualismo a sus últimas consecuencias; él asume ese lugar privilegiado desde donde irradia su propio poder.

Para llegar a esta conclusión es imprescindible, desde luego, la lectura cruzada con Ex captivitate salus y Glossarium ${ }^{53}$, donde emerge la ambigua posición con respecto a Stirner que tanto llamó la atención a un finísimo descodificador de textos como Derrida ${ }^{54}$. El recuerdo de juventud de ambos catedráticos posibilita entonces, de repente, un estrato explicativo más profundo, en el cual los diversos itinerarios

\footnotetext{
kurze Editionsgeschichte, Núremberg, LSR-Verlag, 1997, pp. 18-28. Es muy probable que la lectura de Stirner fuera permitida e incluso alentada por alguno de los dos profesores "heterodoxos" de Attendorn, que ya habían promovido entre los alumnos, por ejemplo, la temprana lectura de La vida de Jesús de D. F. Strauss, cfr. C. Schmitt, ,Solange das Imperium..., op. cit., pp. 30 ss.

${ }^{51}$ J. E. Dotti, "El visitante de la noche. En torno a la presencia de Max Stirner en el pensamiento de Carl Schmitt", en Carl Schmitt, su época y su pensamiento, J. E. Dotti y J. Pinto (eds.), Buenos Aires, Eudeba, 2002, pp. 13-29, aquí pp. 19 ss.

${ }^{52}$ Ibidem, sobre todo pp. 16 ss., 21-26.

${ }^{53}$ Nos limitamos a señalar los pasajes más importantes para futuras investigaciones: ECS, 72, 73, 77 , 78; G, 20, 21, 28, 36, 48, 101, 151, 179.

54 "Lo convoca como a un fantasma de su infancia. Como a un hermano también, un hermano admirable pero desorientado [...] Schmitt reconoce entonces su deuda. Conocer a Stirner lo ha preparado a lo que sucede hoy, y que de otro modo lo habría sorprendido" (cfr. J. Derrida, op. cit., p. 184).
} 
espirituales de la historia alemana que encontramos desolados en 1945 son reconducidos a uno de sus determinantes puntos de inflexión. La figura del "pobre Max" [ECS, 72] reaparece con fuerza, porque en el momento de mayor destrucción, la mirada que reivindica la unicidad irreductible e inalienable de cada ser humano, como verdad existencial, como propiedad intransferible, se nos muestra también en su más pura ambigüedad: la prioridad del gesto existencial de autoafirmación no ha conseguido de momento doblegar el gesto de los propugnadores de la pura inmanencia. El fracaso de Stirner, esa víctima de su propio Yo, es el fracaso de todos.

$* \quad * \quad *$

Cerremos el epílogo: "Berlín, 1907" ha demostrado ser, así me lo parece, una atípica reflexión schmitiana sobre el problema moderno del individualismo como negación de lo político y sobre la complejidad de sus diversas proyecciones culturales y sociopolíticas en Alemania. Lejos de ser un mero divertimento autobiográfico, este inédito ofrece numerosas pistas sobre los avatares del sujeto moderno y la constitución de la subjetividad como instancia soberana en las sociedades capitalistas avanzadas, también sobre alguna de sus transiciones epocales más decisivas, como la del Themenkomplex del genio y el genialismo durante el fin de siècle alemán.

Las pistas, sin embargo, no se siguen de otra manera que asumiendo la descodificación literaria del ambiguo y poliédrico texto schmittiano, que pertenece, como hemos señalado en la primera parte de nuestro estudio, a un turbulento periodo creativo de su obra que sigue mereciendo todavía una mayor atención. El ejercicio de lectura cruzada nunca es fácil ni pleno, desde luego, sobre todo cuando, además de las Respuestas en Núremberg, falta todavía por publicar en nuestro país la pieza críptica por excelencia, esto es, el Glossarium. Del mismo modo, no debiéramos olvidar tampoco que la "personalidad angular" de Schmitt pocas veces se nos mostrará más compleja y calculadora, consciente de que sus palabras no buscan ni el recuerdo de las víctimas, ni corregir sus concesiones antisemitas, ni siquiera expiar la culpa en términos necesariamente cristianos. El soliloquio schmittiano tras 1945 y la profundidad de su meditación como vencido son siempre, antes que una inclasificable autocrítica, una poderosa autoafirmación como jurista, como genuino pensador del derecho, cuya voluntad de transparencia y sinceridad consigo mismo no implican, ni de lejos, que lo vaya a ser con nosotros. 


\section{Berlín, 1907*}

\section{Carl SchMitT}

El maelstrom me sorprendió por primera vez en 1907 cuando, tan pronto como terminé mi Abitur, me apresuré a empezar mi primer semestre en la Universidad de Berlín. Yo no deseaba perder el tiempo: quería trabajar duro y oír a los catedráticos de fama mundial. La verdad es que no sabía lo que me movía e impulsaba. Vivía en casa de unos familiares, una hermana y un hermano de mi padre. Ambos, a su vez, habían sido arrojados por el maelstrom desde el Mosela hasta Berlín. Nada sabía de semejante conexión en el fatum de la familia de mi padre. Como un potrillo hambriento que va a la pradera, yo corrí en seguida en 1907 de un gimnasio humanístico de provincia a Berlín. ¿Por qué me fui a Berlín y no directamente a una universidad del sur o del oeste de Alemania, como hice luego al irme a Múnich y Estrasburgo? ¿Por qué no me fui a Heidelberg como haría mi hermano pequeño siete años después? En Heidelberg habría recibido mis primeras impresiones de la mano de Max Weber. Habría tenido ante mí a un testigo de la ascesis de estudioso protestante y no a los prohombres y arribistas berlineses de la época guillermina.

No empecemos con el "si" y el "habría". Para sus deseos y fantasías, los hombres hacen un uso precipitado del vehículo lingüístico de las irreales oraciones condicionales. A los filósofos de la historia les encanta imaginarse qué habría ocurrido si Marco Antonio hubiera vencido en Accio o Napoleón en Leipzig. Estas son las 1lamadas ucronías, que tienen incluso menos consistencia que las utopías. Imaginarse algo seriamente como acontecido, cuando en realidad no ha ocurrido, para construir un curso de las cosas completamente distinto, es un juego peligroso. Sólo tiene cierto sentido en un espacio de juego reducido y sólo como método heurístico. Nosotros debemos arrepentirnos de nuestros pecados, pero no podemos quitar un trozo del indivisible todo que es el acontecimiento y reemplazarlo por otro trozo imaginado. Querer decir lo que habría podido ocurrir tiene algo de chulesco, y me parece impío querer saber algo que realmente no ha ocurrido. En sus últimas consecuencias, tales combinaciones irreales se me presentan hasta delirantes. Dios ha permitido lo que ha acaecido, y no ha permitido lo que no ha acaecido. Tout ce qui arrive est adorable. Quien ya no sea capaz de enaltecer la omnipotencia de Dios al menos debería enmudecer ante ella.

En Berlín vi un nuevo mundo. Claro que no era ninguna pradera sobre la que pudiera simplemente apacentarse a mi antojo. Pero quizá se trataba de algo más

\footnotetext{
${ }^{*}$ Traducción de Kilian Lavernia Biescas.
} 
elevado. Respetuoso, pisé la universidad: pensaba que era el templo de una espiritualidad superior. Sin embargo, el culto que pude observar ahí era muy confuso y no consiguió estimular mi participación. Sus sacerdotes tenían una relación con el Yo extraña y contradictoria. Era, de forma simultánea, un acorazamiento y un desencadenamiento del Yo. En la contradicción interna de su acorazado desencadenamiento, el suelo por el que caminaban se transformaba en un escenario sobre el que ellos se exhibían. Toda la época era histriónica y, en consecuencia, el templo resultó ser un teatro. Aquí había muchos y grandes eruditos de renombre. También había numerosos ancianos venerables, procedentes de una época menos histriónica. Se trabajaba mucho, frenéticamente, pero también en los teatros se puede trabajar de manera frenética. Lo que vi y me impresionó sobremanera fueron las celebridades que se encontraban justo en la flor de su vida. Entre ellas, fueron dos las que condicionaron con mayor intensidad mis primeras reacciones. Eran muy distintas entre sí, de origen y actitud diametralmente opuestos: el uno, del sur de Alemania, barroco, el otro, de porte prusiano. A pesar de ello, y más allá del caso individual, ambos me hicieron ver la imagen de la problemática del Yo de aquel entonces.

El primero era Josef Kohler, un jurista inconmensurablemente polifacético y docto. Él era el representante abierto y tosco del tipo inclusivo, inclusivo en el sentido del propio Yo. Sus ocurrencias brotaban a granel, ora de forma confusa, ora de un modo brillante y original. Sin embargo, no podía pensar ni decir nada sin remitirse para ello a sí mismo, sin explicarse, representarse a sí mismo o incluir a su Yo en todo lo que pensaba y decía. Con independencia de lo que estuviese hablando, siempre lo hacía sobre sí mismo. La historia del derecho civil se convertía, para él, en la historia de su ocupación con el derecho civil y sus ocurrencias respecto de este tema. Si hablaba del derecho de asilo de los negros bantúes, uno sólo escuchaba: Yo y el derecho de asilo de los negros bantúes. Él lo consideraba elegante, porque se tenía por un gran artista. Su máscara facial y su melena las exhibía con orgullo barroco, por cuanto su parecido se había estilizado a la manera del gran Príncipe Elector. Así se dejaba ver en la cátedra y en los cafés. Los estudiantes se reían y admiraban precisamente esta vanidad suya. Esto sólo alimentaba todavía más su delirio inclusivo del Yo. Sus disertaciones eran borrosas; su entonación se hallaba en un grave desequilibrio fonético con respecto a su principesca máscara barroca. Hablaba de su naturaleza fáustica y había escrito una novela que rápidamente adquirí. En efecto, la portada y la solapa del libro rezaban: Josef Kohler, Una naturaleza fáustica ${ }^{1}$.

Yo leí la novela y me avergoncé del famoso hombre. Se trataba de la historia de amor de un erudito, esbozada de manera descuidada, diluida en una verborrea profesoral, aparentemente autobiográfica, pero también estilizada en exceso, un bosquejo embadurnado de pseudorromanticismo, pseudodemonismo y pseudogenialismo, un glissando con ecos de Goethe, Wagner, Nietzsche, Schopenhauer y Hegel. El héroe

${ }^{1}$ [J. Kohler, Eine Faustnatur, Berlín, Concordia, 1907, 226 pp.] 
se llamaba Wolfgang. Esto era un guiño muy claro a la Goethe-Bildung de aquellos años. Wolfgang completa primero una tragedia gretcheana con la hija rubia de un funcionario llamada Elsa, luego una cosa más demoníaca con una pintora morena llamada Isolda. Durante semejantes exigencias y pese a ellas, Wolfgang escribe un formidable libro científico y obtiene por ello la cátedra en la Universidad de Berlín, sin duda alguna merecidamente y para bien de la humanidad.

Todo esto podría tener algo de infantil y emotivo. Pero la decoración era insoportable, y el héroe, de manera increíble, se las daba de superhombre que demuestra su genialidad a través de una incansable verborrea. Por suerte se subrayaba que era económicamente independiente, de modo que el lector podía estar tranquilo con respecto a la base económica del superhombre. Lo único decisivo era que nada sobrepasara a su propio Yo. La gran bandera del Yo ondea sobre la novela con el lema: "No puedes llegar a ser más que tu Yo, pero este Yo, isea!". El comienzo del último capítulo, cuando nuestro héroe se convierte en catedrático, está encabezado con la siguiente divisa: "Convertido en su propio Yo". En ocasiones, cuando no todo sale a pedir de boca, el héroe se vuelve nihilista. Entonces se habla del nihilismo de la vida y del nihilismo del corazón. Pero todo se arregla rápidamente. El Yo se encarga de ello. Tan pronto como la situación con las dos señoras -Elsa e Isolda- se vuelve incómoda, éstas mueren en un abrir y cerrar de ojos, una detrás de la otra. El héroe se recupera en un viaje por Italia mediante la contemplación artística y finalmente aparece el Ministerio de Cultura prusiano con el llamamiento a Berlín, como la reina de las hadas en un país de las maravillas para eruditos geniales y su Yo más primordial.

La novela posee un determinado significado contemporáneo como síntoma de la irrupción de Nietzsche en amplias capas de la intelectualidad alemana. Por lo demás, uno debería poner semejantes tonterías debajo de la capa del olvido y no mencionarlas más. Pero este hombre era, para mí, el único profesor de derecho en Berlín que se elevaba por encima de los callejones sin salida del positivismo jurídico estatal y del acervo material de los historiadores del derecho, el único que hablaba sobre Hegel y Bachofen y que parecía abrirnos una ventana al vasto mundo. Al final, tampoco yo pude soportar más al loco portador cargado con máscaras del Yo. Tardé bastante en aprender a valorar objetivamente sus originales ocurrencias. Para mí se ha convertido en el primer ejemplo en carne y hueso de la confusión que el delirio del Yo y el concepto de genio han causado en la Bildung alemana.

El segundo caso, Ulrich von Wilamowitz-Moellendorff, el célebre filólogo clásico, es muy distinto. Al principio me fascinó. Su rostro venerable, su actitud aristocrática, la imponente retórica, todo me impresionaba profundamente. Yo no estaba predispuesto en su contra por Nietzsche y me llené de emoción cuando de su boca escuché decir, en una de las primeras clases magistrales, que el escrito ciceroniano De officiis era algo grandioso y no un libro para chiquillos. Él dijo "no un libro para chiquillos" con solemne superioridad, en un tono que era insistentemente festivo pero que, al mismo tiempo, asestaba una puntada polémica. Esto me imponía so- 
bremanera. Por la escuela yo ya conocía el texto de Cicerón y lo amaba desde un estoicismo infantil. Tanto más orgulloso me sentí entonces al oír que no se trataba de ningún libro para niños. A mí me gustaba la actitud autoritaria del gran erudito. Detrás de él me parecía ver a un hombre sumamente experimentado. Reafirmó mi pueril interés por el orador romano que el infalible Theodor Mommsen nos había presentado tan pequeño y raquítico. Pero la alegría por el maravilloso Wilamowitz se desvaneció como con otras tantas sensaciones parecidas que brotan de esta fuente. Al final, sólo quedaron los efectos desde la cátedra, que para un viejo y atractivo pedagogo no resultan difíciles.

La repulsión [Repulsion] que sentí aquí no fue tan repentina como la primera, aquella que surgió del espectáculo del catedrático barroco. Ésta sólo fue definitiva e irreparable cuando, algunos años después, llegó a mis manos un conocido discurso universitario que el distinguido personaje había pronunciado en 1900 con ocasión del cambio de siglo. El discurso es una obra maestra del arte de la disertación académica. Su estructura, su ductus retórico, la abundancia de su conocimiento erudito, todo esto lo convertía en un documento de elevada Bildung humanística. Toda él está labrado y cultivado con tal esmero como descuidado y desaliñado era el bosquejo de la novela de Josef Kohler sobre la naturaleza fáustica. Sin embargo, al citar el Fausto, con el que ambos revisten su optimismo panteístico, los dos son exactamente idénticos, tanto en la orgullosa conciencia del ingente progreso de su época como en el sorprendente entusiasmo con respecto al creciente bienestar y el funcionamiento científico. El consejero secreto prusiano tenía una opinión algo más estricta sobre 1848 que su compañero de Alemania del sur, que coqueteaba un poco con aquel año. El prusiano condenaba tajantemente toda forma de rebelión abierta, pero a cambio ensalzaba los hombres del progreso liberal y encontraba duras palabras contra la reacción. Al servicio militar obligatorio lo llamaba la verdadera y realmente liberadora formación general [allgemeine Bildung] del pueblo. Aunque yo esto no lo creía, tampoco me resultaba molesto. El oscilante ir y venir de sus valoraciones descendía hasta el consumado ductus retórico, incluso parecía hacer revivir el discurso y le otorgaba al propio orador una superioridad olímpica à la Goethe. Así que, en un principio, no tuve nada que objetar.

Sin embargo, cuando el noble personaje empezó a describir en este discurso de 1900 lo que entendía por "tipo de hombre moderno alemán" me pareció decididamente cómico. Este tipo debía representar la formidable antítesis del pobre y oprimido compatriota alemán de épocas anteriores. Al tipo moderno -así se decía literalmente- el bienestar material, la liberación política y el estímulo intelectual le han quitado la tontería de su mirada, y ahora está ahí de pie "con el cuello tan recto, el pecho tan libre y la mirada tan clara". El ritmo de este pasaje se deslizaba en seguida hacia una canción extremadamente banal que muchos entonaban, a lo que yo no podía hacer otra cosa que reír. Detrás del coturno veía una grave pega. Pero no terminaba ahí. El tipo de hombre moderno debía aparecer tal como la pintura gre- 
mial de Rembrandt y Frans Hals mostraba a los libres e impenetrables holandeses. De nuevo, por tanto, nos hallábamos ante una ópera histórica, con figuras históricas bien verdaderas, ya fueran representadas como maestros cantores de Núremberg del siglo XVI o como campeones de tiro holandeses del siglo XVII. En el marco y sobre el suelo de aquel Berlín, todo se convertía en una representación teatral. La vibrante retórica ética no hizo más que acelerar el proceso de escenificación. El único espacio que conocía esta especie de espiritualidad era el espacio escénico. También este distinguido hombre se alzaba sobre su escenario y se producía a sí mismo y a su Yo, sólo que, a diferencia del barroco y sureño Josef Kohler, lo hacía detrás de un mejor parapeto de construcción prusiana.

Mi primera desconfianza brotó con la desamparada germinación de mi propia opinión. Encontró una primera aproximación en la ostentosa máscara del hombre. Me lo quedé mirando y me fui alejando de él con tristeza. Hoy tengo claro que su contención principalmente ética me impresionó mucho más que el desencadenamiento esencialmente estético del otro. Mientras que la máscara de Príncipe Elector del alemán sureño y barroco era ridícula, el rostro aristocrático del noble alemán del norte resultaba todavía burgués, sin duda elevadamente burgués, a saber, elevado en virtud de una publicidad [Öffentlichkeit] generada por el público y el podio. En su origen, el podio había sido un púlpito y se encontraba en una iglesia cristiana. El púlpito se convirtió en una cátedra para lecciones filosóficas y morales. Y, entonces, la cátedra se convirtió en un escenario, por cuanto del escenario se hizo una institución moral y de la institución moral un escenario. La transformación del podio se hizo reconocible en la fisonomía de la época. En el rostro del tipo intelectual de aquellos años coincidían tres rostros burgueses: el de predicador, el de catedrático y el de actor. El denominador común, la línea general, la síntesis se daba a través de la armonización estética. De ello resultaba una tendencia general hacia la máscara goetheana. La máscara goetheana fue la peor desgracia de la época. Con ella se les inoculó a miles de jóvenes entusiastas la ilusión de una potestas spiritualis. Sólo porque el recuerdo de una verdadera potestas spiritualis aún no había desaparecido en mí, me guardé de caer en la imagen ilusoria.

No es difícil ver que el desapego que entonces crecía en mí tomaba como punto de partida una serie de meros juicios de gusto que en un principio todavía se movían enteramente en el terreno de una simple conciencia estética. A este orden de cosas pertenece el que ya no pudiera leer ninguna de las muchas y conocidas traducciones de Wilamowitz de los clásicos griegos desde el momento en que fui capaz de comprender algo de los versos de Hölderlin. Pero aún no había avanzado hasta la plena comprensión de la situación y tampoco sentía la urgencia para ello. Yo sentía la mezcla entre el conservadurismo prusiano y el progreso liberal, entre nacionalismo y humanismo, entre Treitschke y Goethe, entre una marcada autoconfianza y una modestia igual de marcada. Sin embargo, todavía no la sentía con una claridad propia, sino que la percibía tan sólo de manera general como un bochornoso ambiente 
de fallidos equilibrios. Sólo años más tarde, al recordar primero el enorme impacto y luego la posterior decepción que me causó aquel comentario sobre Cicerón, me di cuenta de la razón más profunda. ¿Qué podía saber un hombre tan bien situado, tan contenido y acomodado como este consejero secreto berlinés del año 1907 sobre un orador político, cuya existencia toda se encuentra, en cada palabra suya y en cada acontecimiento que vivió, hasta en los detalles de su muerte y de su tratamiento mortuorio, en una completa situación de guerra civil? El gran erudito, el mismo que hablaba de un modo benévolamente liberal sobre 1848 y de manera elogiosa sobre Cicerón, jamás había estado un solo segundo de su vida en el peligro en que Cicerón lo estuvo la suya entera. Jamás había caído en aquel ámbito que se alza más allá de las líneas amigas. A cualquiera, empezando por el gran erudito, le habría parecido inconcebible que su nombre se encontrara en una lista de proscritos o que él mismo estuviese proscrito y fuera del derecho. Sobre estas experiencias de la guerra civil sabía probablemente menos incluso que Theodor Mommsen, quien había conservado intensos recuerdos de 1848 y había participado en el conflicto constitucional prusiano de 1862-65. Al final, la inconsistencia existencial entre la situación de un catedrático liberal-conservador berlinés de 1907 y la de un adversario político de Catilina, Julio César y Marco Antonio hizo que la retórica áulica del primero terminase pareciéndome vacía y enmascarada. La máscara más distinguida me entristeció más que el aspecto tosco del otro erudito, que presumía de ser tan genial.

No he mencionado los nombres de dos reconocidos catedráticos alemanes por mor de sí mismos. No es mi intención desprestigiarlos o utilizar sus figuras para explicar el fenómeno universalmente humano del egoísmo, de la vanidad o de un individualismo avanzado. A ellos, como a algunos otros profesores de Berlín, les estoy obligado a la gratitud. Pero ninguno de ellos me conquistó interiormente. Muchas personas en Berlín -y no sólo los dos catedráticos aludidos- me han producido la profunda repulsión de la que sólo fui consciente a la vista de ambas precisas figuras. Sin embargo, en su diversidad, ambos reflejaban la oposición entre un desencadenamiento del Yo esteticista y motivado artísticamente y otro protestante y norteño de tipo ético. Estos eran los dos lados de la contradicción interna que padecía el Yo-entero alemán en la situación histórica de aquel entonces. Esta impresión general es la que aquí está en juego. En semejante Yo participan todos aquellos que intervienen en la situación histórica, los que se avienen con y se adaptan a ella. Acto seguido, muchos pequeños Yoes empíricos se tienen por Yoes y se transforman en la máscara que llevan puesta. Así es como se impone el Yo-entero a la situación histórica. Esto es a lo que me refería cuando hacía alusión al desencadenamiento y acorazamiento del Yo, de los que recibí entonces mis primeras impresiones en Berlín, cuando creía estar saltando como un potrillo sobre la pradera.

Ahora sólo hace falta hablar de mi propia situación personal. De hecho, a cada impresión pertenecen en rigor dos imágenes, de modo que después echaré una mirada a mí mismo en tanto que el otro compañero del encuentro que suscitó tales 
repulsiones. Yo era un joven oscuro de origen humilde. Ni la clase dominante ni las fuerzas de la oposición me habían seducido. No me afilié a ninguna asociación estudiantil, a ningún partido político ni a ningún círculo, y tampoco fui cortejado por nadie. La pobreza y la modestia eran los ángeles protectores que me mantenían en la oscuridad. Con respecto a nuestra impresión, esto significa que, estando totalmente a oscuras, yo miraba desde la oscuridad a un espacio totalmente iluminado. Para un espectador y observador esta es la mejor posición. Los actores en el espacio totalmente iluminado no me obligaban a hacer nada. Ellos tenían en mente a otros espectadores muy distintos de mí, y por tanto, frente a mi persona, se comportaban tal cual eran. De este modo era capaz de verlos mejor que ellos a sí mismos. Nada sabemos de cómo en la vida social e histórica de los hombres se comportan los procesos microfísicos con respecto a los acontecimientos macrohistóricos. En cualquier caso, estar en la oscuridad suponía una ventaja. L'obscurité protège mieux.

Otra ventaja aún más grande era que yo no pensaba salir de la oscuridad para buscar la luz. Yo era un joven católico del oeste de Alemania que llevaba dentro de sí un fuerte recuerdo del Kulturkampf bismarckiano a través de sus padres, abuelos y familiares eclesiásticos. El Kulturkampf no había sido una sangrienta guerra civil. Sin embargo, el conflicto había sido lo bastante agudo como para distanciar a un joven católico de las capas dominantes. En mi juventud había tanta sustancia y vínculo religiosos que las distintas manifestaciones de la creencia en el Yo pasaban a mi lado como extrañas máscaras. Ni el desencadenamiento del Yo esencialmente estético de Kohler ni el acorazamiento del Yo fundamentalmente ético de Wilamowitz me conmovieron en mi fuero interno. En el fondo, yo entonces no los entendía en absoluto, y fueron necesarios numerosos encuentros personales y un largo proceso de confrontación dialéctica antes de que pudiera comprenderlos de verdad. De todo ello no surgió ciertamente una enemistad, ni siquiera una oposición consciente, pero sí la distancia suficiente con respecto a los mitos del Reich bismarckiano y al ambiente nacional-liberal de la Universidad de Berlín. Yo participaba en el espectáculo que me ofrecía Berlín sin tener que identificarme con él. Esta era la mejor disposición para un observador y una buena posición para un espectador de mi naturaleza.

Ahora bien, la buena posición no era de ningún modo cómoda o confortable. A fin de cuentas yo no era un extranjero indiferente. Tampoco era un espectador meramente interesado en lo estético, un schopenhaueriano que se mantiene alejado de un mundo acuciantemente ciego con ayuda de la máxima "espléndido de ver, pero horrible de ser". No es mi estilo ni mi competencia. La fuerte repulsión que experimentaba no daba lugar a un placer por el rol de espectador. El sentimiento de tristeza que me invadía acrecentó mi distanciamiento y despertó la desconfianza y la extrañeza entre los demás. Una capa dominante considera heterogéneo a cualquiera que, cuando al tomar contacto con ella, se muestre no afortunado sino afligido. Un ambiente cerrado excluye despiadadamente a todo aquel que no se encuentre cómodo en su interior. Lo coloca frente a la alternativa de adaptarse o alejarse. Sus mudas 
alternativas son muy efectivas, por lo general mucho más efectivas que una interpelación formal. Así que me quedé fuera. Yo tomé mi camino y tuve que ver cómo me las arreglaba. En ello me encontré primero con un joven compañero de oficio alemán que me pareció, después de aquellos dos catedráticos, verdaderamente refrescante: Max Stirner. 